\title{
PRESCHOOLERS' SEARCH FOR EXPLANATORY INFORMATION WITHIN ADULT-CHILD CONVERSATION
}

\author{
by
}

\author{
Brandy N. Frazier \\ A dissertation submitted in partial fulfillment \\ of the requirements for the degree of \\ Doctor of Philosophy \\ (Psychology) \\ in the University of Michigan \\ 2007
}

Doctoral Committee:

Professor Susan A. Gelman, Co-Chair

Professor Henry M. Wellman, Co-Chair

Professor Annemarie Sullivan Palincsar

Research Scientist Evelyn Margaret Evans 
(C) Brandy N. Frazier

All rights reserved 2007 


\section{DEDICATION}

To my papa, Robert Brown, who always saw the best in people.

Thank you for seeing the best in me. 


\section{ACKNOWLEDGEMENTS}

This dissertation would not have been possible were it not for the support, help

and guidance of many people. First and foremost, I am especially grateful to my research advisors and co-chairs: Susan Gelman, who patiently answered every single one of the hundreds of e-mails I sent her over the past five years and who helped me keep this process in perspective by reminding me often of how far I had come; and Henry Wellman, who greeted every one of my drafts with enthusiasm that made me want to work on the next one. Thank you both for always being excited about my ideas. I also want to thank my other wonderful committee members, Margaret Evans and Annemarie Palincsar, for their encouragement and thoughtful insights.

I would also like to thank the children, parents, teachers and staff at the University of Michigan’s Children’s Centers, the YMCA Early Childhood Program, Little Folks Corner, Concord Preschool, Chelsea Children’s Co-op Preschool, Bemis Farms Preschool, Back to Basics Montessori Preschool, Country Day Montessori School, and the Charles Brown and Buckeye Head Start programs, for their support and participation in my project. Meeting and talking with all of the delightful preschoolers in these programs was my favorite part of this endeavor. I would also like to thank the students of the Psychology Undergraduate Subject Pool for their participation in this project. 
I would like to acknowledge the National Science Foundation for their graduate research fellowship funding, and Rackham Graduate School and the Psychology Department for the dissertation grants that supported this research. In addition, I am also grateful for support from NICHD grant HD-36043 to Susan Gelman, grant HD-22149 to Henry Wellman, and a McDonnell Foundation grant to Henry Wellman and Susan Gelman.

This work would not have been possible without the invaluable help of many tireless research assistants who spent hours helping with this project and listening to me talk about how cute preschoolers can be. Thank you to Sara Miller, Liz Hrivnak, Jenna Eisen, Katina Stowers, Kristin Rohrbeck, Jason French, Courtney Petersen, Emily Haas, Jessie Emerick, Shelley Housey, and my superstar, Laura Dean.

Special thanks go to the incredible fellow graduate students I have been lucky to share classes, conversations, meals, and houses with over the past five years. I am especially grateful to Medha Tare, Felicia Kleinberg, Kate Fiori, and Jenny LaBounty for your endless support and willingness to discuss and share my enthusiasm for low-quality reality television. I would also like to thank Emma LaBounty for always putting a smile on my face. And finally, I am especially grateful to my best friend, Amy Rauer, for being the wind beneath my wings and always knowing what to say when I needed encouragement.

Without the love and support of my family, this experience would not have been possible. Dad, thank you for calling often to check on me, and Mom, thank you for volunteering to do anything you could to help. Thank you both for always believing I am capable of anything. Special thanks to Bonnie Wells, for all your support and confidence 
in me. And finally, thank you Alex, for your love and endless patience throughout this process. Thank you for the many hours you have spent driving between Bloomington and Ann Arbor to provide me with the hugs, jokes and silly dances that kept me sane. 
TABLE OF CONTENTS

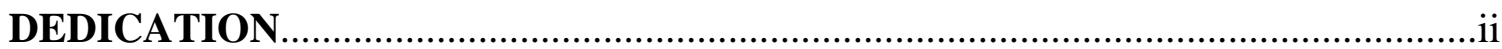

ACKNOWLEDGEMENTS....................................................................................ii

LIST OF TABLES..............................................................................................

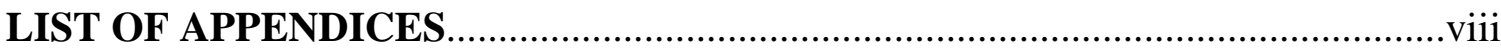

\section{CHAPTER}

I. Introduction: Preschoolers' Search for Explanatory Information within Adult-

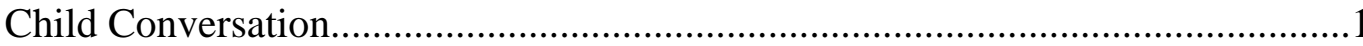

II. Study 1: CHILDES Study Examining Adult-Child Conversation Following Children's Why and How Questions..

III. Study 2: Experimental Study of Children's Responses Following Explanations versus Non-Explanatory Answers....................................................................26

IV. Introduction: Adults' and Preschool Children's Preferences for Explanatory Detail.

V. Study 3: Adult Ratings of Explanations and Non-Explanations that vary in Explanatory Detail.

VI. Study 4: Experimental Study of Children's Satisfaction with Different Levels of Explanatory Detail................................................................................................62

VII. General Discussion....................................................................................

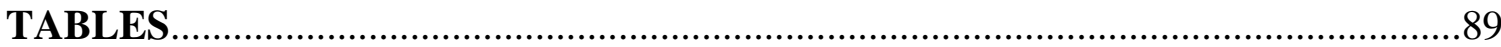

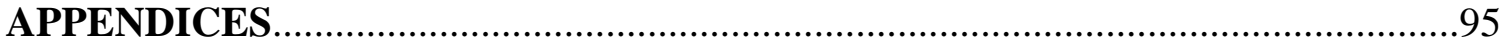

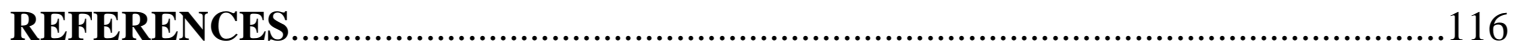




\section{LIST OF TABLES}

\section{TABLE}

1 Study 1: Percentage of Child Responses Following Adult Explanations versus

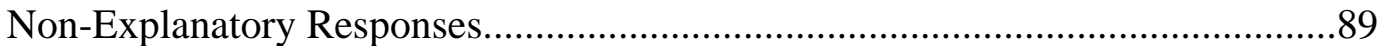

2 Study 2: Percentage of Child Responses Following Adult Explanations versus

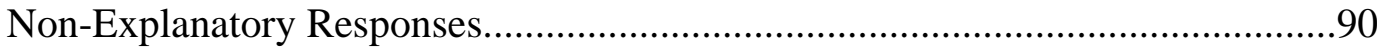

3 Study 3: Adult Average Ratings of Each Type of Answer.................................91

4 Study 3: Percentage of the Time Adults Recalled Each Answer Segment...........92

5 Study 4: Percentage of Child Responses Following Adult Explanations versus Non-Explanatory Responses..............................................................93

6 Study 4: Percentage of the Time Children Recalled Each Answer Segment........94 


\section{LIST OF APPENDICES}

\section{APPENDIX}

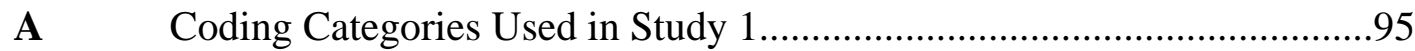

B Explanations and Non-Explanatory Answers Given in Response to Child

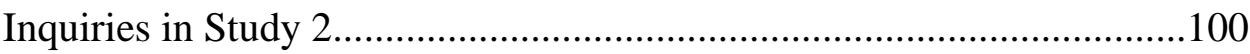

C Coding Categories Used For Child Responses in Study 2......................102

D Answers Used in Study 3 and Study 4: Three Types of Explanations and

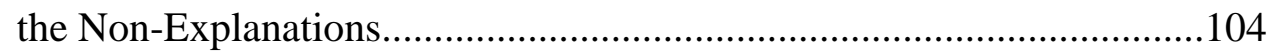

E Coding Scheme for Study 3 and Study 4 Recalled Answers...................109

F Coding Categories Used for Child Responses in Study 4......................112 


\section{CHAPTER I}

\section{Introduction: Preschoolers’ Search for Explanatory Information within Adult-Child Conversation}

Explanatory understanding allows us to see how the world works and to predict and make sense of events, behaviors, and outcomes in our environment. For scholars who focus on person's naïve theories, explanation is arguably central to theory-based conceptual knowledge (Carey, 1985; Murphy \& Medin, 1985; Wellman \& Gelman, 1998). Even young children theorize and explain, and they do not do this by passive means alone. They actively search for causal explanations and knowledge. Children’s questions and the answers they receive to them can illuminate this explanation-building process. Yet surprisingly little is known about young children's search for explanations and even less is known about how they respond to the information they obtain. The current research examines young children's questions and the reactions to the answers they receive within the context of adult-child conversation as means for exploring the active role that children play in successfully obtaining explanatory information.

There are many reasons to believe that information gained through child-initiated conversational exchanges plays an important role in their conceptual development. Empirically, children's questions are frequent and striking during the preschool years (Chouinard, 2007; Hickling \& Wellman, 2001) at the time children are making great strides in assembling explanation-rich naïve theories, functional understandings, and knowledge frameworks (Carey, 1985; Wellman \& Gelman, 1998). Conceptually, 
children have often been described as specifically motivated to actively pursue explanatory information, a motivation that has been variously characterized as an innate "theory drive” (Gopnik, 1998), a curiosity about the world shared by both children and scientists (Simon, 2001), or a desire to resolve disequilibrium or discrepancies between past experience and present events (Piaget, 1954; Isaacs, 1930), among others. Taken together these descriptions provide a strong argument for closely examining how explanatory motivations are manifested within children’s everyday behavior. Hence, my central question: How does childhood explanation-seeking actually work?

In the present studies, I examined the patterns of conversational exchange between child and adult informants to clarify how children seek out and respond to explanatory information. I focus on situations where children are actively requesting information from an adult and I examine how they react to the adult's answer to gain insight into whether and when children are preferentially seeking explanations over other types of responses. My background assumption is that one of the most important sources of explanatory information potentially available to children is the knowledge they can elicit from more expert conversational partners. Asking Causal Questions

In order to test the hypothesis that children ask causal questions with the intention of obtaining explanatory information, we must first establish whether young children appreciate specifically causal information. Early research on children's cognitive development argued that children did not have a true understanding of causality until 7 or 8 years of age. Support for this point of view came primary from Piaget (1930), and Werner and Kaplan (1963), whose research used tasks involving physical causality. 
Results from these studies seemed to show that young children were aware only of the temporal relationship between two events and were unable to differentiate cause from effect.

In the past thirty years, a rich literature has emerged confirming that children have an understanding of causality from a much younger age than previously suggested. Classic research, such as that by Shultz and Mendelson (1975) and Bullock and Gelman (1979), demonstrated that children as young as 3 years old use covariation information and temporal order to reason about physical causality. More recently, Gopnik and colleagues have demonstrated young children's abilities to make causal inferences, using a novel toy called a blicket detector, which lights up only when certain "blicket” blocks are placed on it (for a recent review of this research, see Gopnik \& Schulz, 2004). This line of research has been extended to demonstrate infants’ abilities to make causal inferences (Sobel \& Kirkham, 2006).

However, this contemporary research on children’s causal reasoning abilities has not addressed if and how children actively seek causal information. One fundamental means for doing so is via language, and specifically, causal questions. The emergence and structure of children's questions was initially studied exclusively from a linguistic perspective, including classic research by Klima and Bellugi (1966) and Brown (1968), who investigated developmental changes in the grammatical structure of children's questions, and work by Tyack and Ingram (1977), Cairns and Hsu (1978), and Bloom, Merkin, and Wootten (1982), who investigated the order of acquisition of different forms of children's questions (i.e., using what, where, and who prior to using how, why, and when). 
More recent research begins to examine the content of children's conversations, including their questions, as evidence for their understanding of causal relations. Hood and Bloom’s (1979) analysis of longitudinal samples of speech from eight children provided initial evidence that from as young as $2 \frac{1}{2}$ years, children spontaneously talk and ask about causal intentions and motivations in the course of everyday conversations. Most importantly, children talked about causal events in systematic ways that demonstrated their understanding of the relationship between causes and effects, providing support for the idea that young children have an early understanding of and interest in causal knowledge.

Research by Callanan and colleagues further examined the content of children's everyday language as way of gaining insight into their development of causal knowledge (Callanan \& Oakes, 1992; Callanan, Perez-Granados, Barajas, \& Goldberg, 1999). Callanan and Oakes (1992) asked mothers of 3-, 4-, and 5-year-olds to keep a diary of their child's requests for explanations for a period of two weeks. Analysis of the diaries revealed that children as young as 3 years were asking their mothers causal "why” and "how come” questions about a variety of phenomena in their everyday lives. Children requested explanations about mechanical, natural, and social phenomena, providing evidence that children's everyday question-asking extends across several domains. This first study was with Anglo mothers; the same diary methodology was replicated with higher- and lower-education Mexican-descent families with similar results (Callanan et al., 1999).

Additional information regarding the content of children's causal questions comes from two studies using longitudinal transcripts from the CHILDES database (Chouinard, 
2007; Hickling \& Wellman, 2001). Hickling and Wellman (2001) examined transcripts from 4 children who were recorded between the ages of 2.5 and 5 years. They searched for instances of children's use of causal terms (such as because, how, so) within children's statements and questions, and compared the target entity of the child's explanation (e.g., person, animal, object) to the explanation or explanatory mode the child used (e.g., psychological, biological, physical). The patterns with which children matched explanations to target entities provided evidence for the presence of domainspecific frameworks of knowledge within which children were able to use multiple modes of explanation appropriately with both constraint and flexibility (Hickling \& Wellman, 2001). For instance, children described the behavior and properties of objects only in terms of physical causality, but when the target entities were persons, children appropriately used physical, biological, and psychosocial modes of causality. In other words, children did not randomly pair explanatory modes to target entities, nor did they match one mode of explanation exclusively to one type of target entity.

Chouinard (2007) took a different approach to examining children’s questions within transcripts from the CHILDES database, focusing on how children generally use questions to obtain information. Chouinard (2007) used the transcripts of 4 preschoolaged children (3 of whom overlap with those used by Hickling and Wellman, 2001), to examine every question voiced by these children during the language samples. Chouinard found that the majority of children's questions were information-seeking (as opposed to attention-seeking, action-seeking, or asking for permission). These information-seeking questions were frequent, with an average of 76 per hour, and 
included requests for many different types of information, with questions about activities and labels being the most common.

Chouinard (2007) also coded whether children were requesting isolated facts or more complex explanatory information. At all ages, fact-based questions were more frequent, but there was a general increase in the proportion of questions that requested explanations as the children got older. While 1-year-olds asked no explanation-based questions, at age 5, an average of $30 \%$ of the children's questions were requests for explanations. Further, around age 3, each child demonstrated a relative increase in the proportion of explanation-based questions they asked, suggesting that this may be an age when children are particularly interested in causal information, a result that fits with Hickling and Wellman’s (2001) data in which children used more causal speech at 3 years of age than at 2 or 4 years.

Overall, these studies provide evidence that children are not only able to ask causal questions early, but that they also have the ability to ask appropriately situated questions across a variety of domains. This early emerging and sophisticated skill is potentially a powerful tool for acquiring explanatory information. However, are children's questions actually functioning as the useful tool they have the potential to be? Examining adults’ responses is an important step in addressing this question.

\section{Adults'Responses to Children's Questions}

The research from Callanan and colleagues (1992, 1999) and Chouinard (2007) also began to examine the nature of adults' responses to preschool children's questions. Within the daily dairy methodology employed by Callanan and Oakes (1992), adults’ provision of explanations in response to their children's questions varied with the age of 
the child: mothers of 3-year-olds reported responding with a causal explanation 32\% of the time, mothers of 4-year-olds responded with a causal explanation $61 \%$ of the time, and mothers of 5-year-olds responded with a causal explanation $54 \%$ of the time. Mechanism explanations (describing intermediate steps as a way of explaining how something works) were the most frequent, followed by prior cause explanations (mentioning a prior event or state that caused the asked-about phenomenon) and consequence explanations (mentioning a purpose or an event/state that will occur later in time than the asked-about phenomenon). No significant age effects were found for these different types of explanations, suggesting that parents provide a variety of different explanations in response to children's questions, regardless of the age of the child. (See also Callanan et al. (1999) for similar results from Mexican-descent mothers.) Chouinard (2007) found related results concerning the informative nature of mothers' responses. Within the longitudinal transcripts, children's information-seeking questions (collapsed across fact-seeking and explanation-seeking questions) received an informative reply (either immediately or eventually following the child re-asking the question) between 64$79 \%$ of the time, depending on age.

\section{Children's Responses: A Key Component}

This prior work begins to show that children's questions often function as an effective tool for prompting adults to provide information, and that their questions include causal ones that can prompt for explanatory information. However, that research fails to address how children react to the adult responses they receive to their questions. From both a learning perspective and a conversational perspective, question-asking conversational exchanges would seem to encompass three critical steps. In the process of 
learning, these steps include: a) an initial state, b) informational input, and c) revision of knowledge or adjustment of the system. Further, these three steps can be seen as corresponding to three steps in conversation: a) the child's initial question (e.g., "Why is he wearing a red nose?”), b) the response the child receives (e.g., "People don't usually wear red noses like that”), and c) the child's reaction to this response which could range from either their acceptance of the information and learning from it to rejection of the response. While these three steps are a simplification of the complex (and often much messier) processes of learning and conversation, they provide a useful framework for examining children’s conversation-based learning.

Moreover, the third component of these processes seems especially important for two reasons. First, the nature of children's reactions to the answer/response they receive critically informs us about the nature of their initial question. For instance, perhaps the function of the question from the child's point of view is simply to engage adults, or merely to keep the conversation going. In this case, any conversational response from the adult might be fine or perhaps a particularly long response would be especially satisfying. (Parents often suspect this is the child's motive at the peak of preschool-aged whyquestion asking, when it can seem that no matter what the parent says, the child repeatedly asks, “Why?” “Why?’ “Why?”) However, alternatively, children might be genuinely seeking explanatory information. If this is the case, then they should react differently when they receive an explanation versus when they receive some type of nonexplanatory response. Information about the third step in the conversation, how children react to the answer they receive, is needed to address these possibilities. 
Second, in order to gauge when adult answers are effective, one must know how the information they provide is perceived by the child who has asked the question. To begin with, is the question-asking child satisfied or dissatisfied with the answer he/she receives? Previous research has measured children's preferences by directly asking them to evaluate different types of explanations using forced choice tasks. But it is an open question as to how this process works in everyday life and particularly in everyday conversations initiated by the child. In this context, it is critical to examine how children react to the responses they receive from their conversational partners so that we can gauge how the question-asking actually influences the asker.

As arguably crucial as this third component appears to be, we know very little about it. Chouinard (2007) provides an initial glimpse by examining instances when the four children she analyzed persisted in repeating the same question multiple times in a row. She found that this behavior was much more frequent following non-informative adult responses than following informative ones. This provides preliminary support for the idea that children are often asking questions (largely factual questions in her data) with the goal of obtaining information, rather than just repeating a question to get attention or for their own enjoyment.

In the present research, I focus on children's causal questions and requests for explanatory information and I look much more fully at children's reactions to the answers they receive. In Study 1, I do so using longitudinal transcripts of everyday conversation. In Study 2, I create a methodology for bringing this process into the lab to better examine, with more effective control, the relationship between children's questions, the responses they receive, and especially how they react to those responses. Next, I shift the 
focus from examining children's reactions to explanations versus non-explanations, to examining adults' (in Study 3) and children's (in Study 4) satisfaction with explanations that vary in their level of explanatory detail. 


\section{CHAPTER II}

\section{Study 1: CHILDES Study Examining Adult-Child Conversation Following Children's Why and How Questions}

Study 1 examined adult-child conversations following preschoolers' causal why and how questions from longitudinal transcripts recorded in naturalistic situations within the CHILDES database. While prior studies have examined the content of children's questions (causal and non-causal) using the CHILDES database (Chouinard, 2007; Hickling \& Wellman, 2001), I use a larger sample and additionally focus on children’s reactions to the answers they receive to their causal questions.

I concentrated on how and why questions (although children may have also asked causal questions that did not use why or how) for several reasons: from an early age, these questions account for many of young children's causal interrogatives (Hood \& Bloom, 1979); consequently previous studies have also focused on these types of child questions (Callanan \& Oakes, 1992; Hood \& Bloom, 1979); and how and why questions are easy to search for and easy to identify as causal. As outlined previously, I examined three steps of conversation: the initial causal why or how question asked by the child, the adult's response, and the child's reaction to the adult's response. However, my focus concerns the child's reaction to the adult's response, where I test several focal hypotheses.

My primary hypotheses concern how different types of adult responses affect whether a child continues or discontinues that conversational exchange. If children are actively seeking explanatory knowledge using questions, one would expect them to react 
differently depending on whether or not they have received a causal explanation from their adult conversational partner. Specifically, if children are seeking explanations, they should be satisfied when adults give explanations and not satisfied when adults give other types of non-explanatory responses. If this is the case, I expect that children would be more likely to re-ask their questions (showing continued curiosity) or provide their own explanation (showing dissatisfaction with information provided) upon not receiving an explanation. Conversely, if children have been given an explanation, I expect that they will be more likely to agree (showing explanatory satisfaction) or to ask an additional question that is different from the original question, but building on the same topic (showing satisfaction and continued interest in the explanation).

Two alternative hypotheses deserve consideration. First, children may ask questions simply to try to extend the conversation, in which case any adult response would be satisfying and children should show a similar pattern of responses following both explanations and non-explanatory adult responses. Second, children may be responding based on the length of the adult response rather than the explanatory content. If children are motivated to elicit simply as much speech as possible from their adult conversational partners, they should find a longer answer more satisfying than a shorter answer. In this case, children's responses should vary based on the length of the adult response; children should be motivated to ask additional questions when adult responses are short in length and be less likely to ask additional questions when adult responses are long.

I also examined the pattern of child responses in relation to the form of the explanation that an adult gives. If children find one type of explanation more appealing 
or interesting than another, then they may be more likely to ask a follow-up question explicitly for that type of explanation, continuing conversation on the topic. Here I explored whether mechanism explanations, which have the potential to provide rich information about the process underlying a causal relationship (e.g., "The puzzle made noise because there's a little speaker that turns on when you fit the piece into the right spot”), would generate more follow-up questions than a single event mentioned in a prior causal event explanation (e.g., “The puzzle made noise because you put the piece in”). Au and Romo’s (1999) research suggests the possibility that children may find the mechanism explanations particularly satisfying.

\section{Method}

\section{Participants}

The initial data encompassed all conversations including child causal how and why questions from longitudinal transcripts of six children from the CHILDES database (MacWhinney \& Snow, 1985, 1990). The CHILDES database consists of samples of children's conversations with parents, siblings, and occasional visitors during everyday activities in the home setting. The samples were recorded every 1-3 weeks for periods ranging from 30 minutes to two hours. The six children included were Adam, Sarah, Abe, Naomi, Mark, and Ross (Brown, 1973; Kuczaj, 1976; Sachs, 1983; MacWhinney, 1995). The age range for the transcripts initially began at ages 2 years, 3 or 4 months and continued through ages 5 years, 1 or 2 months for four of the children. Because Mark and Ross are siblings, their transcripts cover a wider age range, from 2 years, 6 months through 8 years for Ross and from 7 months to 5 years, 6 months for Mark.

These six children were selected because their data included a large number of 
transcripts within the ages of 2 through 4 years, and the transcripts were recorded in naturalistic settings rather than structured tasks (e.g., a researcher-prompted story book reading). While few, these 6 children do vary on gender ( 4 boys and 2 girls), ethnicity (5 Caucasian, 1 African American), and family occupational status (4 children from academic families, 1 child from a non-academic, middle class family, and 1 child from a working class family).

Procedure

582 longitudinal transcripts (210 transcripts for Abe, 55 for Adam, 137 for Sarah, 93 for Naomi, and 87 for Ross/Mark) were searched for all utterances containing the target words how and why. All utterances containing how and why that were voiced by adults or voiced in statements were removed. In addition, all questions that were incomplete or included unintelligible portions were set aside. The remaining child questions were then reviewed to eliminate clear-cut instances where how and why were not being used causally. This led to the elimination of questions such as "How are you?" “How does that feel?” “How about that?” and “How much milk?” In addition, I also eliminated any questions voiced by children when they were younger or older than the age range of 2 years through 4 years because data outside of this range was limited to only a few of the children. The final sample consisted of 3,162 children's causal why and how questions (948 questions for Abe, 1,202 for Adam, 358 for Sarah, 68 for Naomi, 142 for Mark, and 444 for Ross).

\section{Coding}

The coding scheme encompassed three steps of conversation: the initial causal why or how question asked by the child, the adult's response, and the child's reaction to 
the adult's response. All coding was conducted by examining the conversational sequence within the full transcript. This allowed the coders to read as much of the previous conversation as needed to gain an understanding of the context and meaning of each conversation.

Child questions. The child's question was coded as "why” or "how" and either simple (consisting of only one or two words, such as “Why?” or “How come?”) or complex (including a reference to the subject of the how or why question, such as "Why not my cracker talk?”).

Adult responses. The adult responses were initially coded into one of ten categories including: providing an explanation, providing on-topic non-explanatory information, redefining or correcting assumptions underlying the child's question, confirming/agreeing with the child's question, asking a clarification question, redirecting the question to someone else, saying “I don’t know," saying simply "Because” or "Because I said so" without further explanation, changing the topic, or not responding. The purpose for these extensive initial categories was to provide a comprehensive list of all possible adult responses in order to help coders distinguish between explanations and other types of responses that might include on-topic information, but were not explanatory. The analyses, however, focus exclusively on the key contrast between adults' provision of explanations (e.g., CHILD: “Why you put yogurt in there?” ADULT: “Yogurt's part of the ingredients”) versus adults' non-explanatory answers (e.g., CHILD: "Why does he push this?” ADULT: "He’s just pushing it”). For these analyses, the nonexplanatory answers collapse across all the other initial categories (except explanations) 
mentioned above. Appendix A provides additional examples of explanations and nonexplanatory answers from the data.

If the adult's response was an explanation, the form of the explanation was coded into one of five categories: mechanism (e.g., “It doesn’t fall off because it’s stuck through the paper”), prior causal event (e.g., "I think he heard a big noise”), consequence (e.g., “So his feet won’t get cold”), current state of world (e.g., "Because those are pretty colors”), or other (e.g., "You just don’t do it that way”); see Appendix A for complete descriptions and examples. These categories were based on those used by Callanan and Oakes (1992) with revisions. One revision was adding the category, current state of the world to deal with frequently encountered explanations that did not explicitly refer to an event occurring in the past or a future consequence, but instead focused on the state or quality of a current situation. (However, if a current state of the world explanation included description of a mechanism, it was coded as mechanism explanation.)

Child reactions. The child's response was coded into one of eight categories, including: a) agrees with adult response, b) asks a follow-up question, c) re-asks original question, d) provides own explanation, e) disagrees with adult response, f) provides additional on-topic details, g) changes topic, and h) no response. To give a hypothetical example, if the child’s initial question was "Why did he laugh?” an adult might respond "He thought of a funny joke” to which the child might react in several different ways. For example, the child might say, “Oh, I think so, too” which would be coded as agreeing with the adult response. Or perhaps the child might ask "But what made him laugh?” which would be coded as re-asking the question. If the child asked, "Why did he think of a funny joke?” this would be coded as a follow-up question. Finally, if the child said, "I 
think someone tickled him,” this response would be coded as providing his/her own explanation. See Appendix A for more detail on these coding categories and examples from the data.

Reliability

Inter-rater reliability was established using randomly selected samples of $20 \%$ of each child's total causal questions. Two persons independently coded each of these $20 \%$ samples and if a satisfactory level of agreement was not achieved, disagreements were discussed and an additional 20\% sample was selected for reliability coding. For child questions, which were coded as simple or complex, there was 99\% agreement overall (across all 6 children) and a Kappa of .99. Coding for adult responses, as explanations or non-explanatory answers, had an overall (across all 6 children) 95\% agreement, with a Kappa of .90. For coding the explanation form of adults’ explanatory responses (e.g., mechanism vs. prior cause, etc.), there was 77\% agreement, with a Kappa of .68. Focally, for all the child reaction codes there was 85\% agreement, with an overall Kappa of .82. Reliability was also calculated for each child response coding category; percent agreement ranged from 93\% to 99\%, with Kappas ranging from .64 to .97. Reliability was also confirmed for each individual child, with Kappas ranging from .75 to .91. All of the Kappas fall within "substantial” (.61 to .80) levels of inter-rater reliability and 50\% of them fall within “near perfect” (.81 and above) levels (Landis \& Koch, 1977).

Results

The small number of children in this study presents several analysis challenges. In order to increase the reliability of the statistical tests used, data were pooled across children, making the utterance instead of the child the basic unit of analysis. With regard 
to the independence of such data, Bakeman and Gottman (1997) suggest that successive events (e.g., multiple utterances from the same child) measured in naturalistic settings may be regarded as independent for the purposes of statistical analysis as long as (a) observers make separate (and presumably independent) decisions when coding each event, and (b) the coding system consists of mutually exclusive and exhaustive categories. Both of these stipulations apply to this coding.

In an effort to avoid reporting findings that are driven by the results of only one child, the inferential statistical analyses followed several steps. Initially, I used an omnibus chi-square to test for differences between all the patterns of child reactions to adult responses. Whenever this chi-square was significant, it was followed up by examining proportions of responses to individual categories. Here I used $z$-scores to assess the significance of differences between paired proportions. The $z$-scores compared the relative proportions of coding categories to each other and across time. For example, for my primary hypotheses, proportions were created by dividing the frequency of each type of child reaction following an explanation by the number of explanations that children received. The same was done for child reactions following non-explanations, with the denominator being the number of non-explanations received.

For all the analyses, I adopted a conservative level of significance $(p<.01$, two tailed), to reduce the possibility of Type 1 error resulting from multiple comparisons and because of the large numbers of utterances contributing to the proportions. In addition, to be considered as significant, the comparison had to be in the same direction for at least 5 of the 6 children individually. For examples of studies that use $z$-test analyses in this manner, see Hickling and Wellman (2001) and Lagattuta and Wellman (2002). 


\section{Children's Questions and Adult Responses}

Overall, the 6 children in the sample asked simple questions (consisting of only one or two words) $31.2 \%$ of the time, and complex questions (including a reference to the subject of the how or why question) $68.8 \%$ time. The relative percentage of complex questions significantly increased over time, with 53.6\% of 2-year-olds’ questions being complex, increasing to $69.3 \%$ at age $3(z=-7.11, p<.001)$ and to $79.2 \%$ at age $4(z=-$ 5.27, $p<.001)$.

With regard to adults’ provision of different types of answers, overall, adults provided an explanation $36.7 \%$ of the time, with the remaining $63.3 \%$ of adult responses being non-explanatory. The percentage of the time that children received an explanation decreased with age, with 2-year-olds receiving an explanation $40.7 \%$ of the time, 3-yearolds receiving an explanation $38.3 \%$ of the time and 4 -year-olds receiving an explanation $30.7 \%$ of the time. Only the decrease from age 3 to 4 was significant ( $z=3.81, p<.001$ ). Do Children React Differently to Explanations versus Non-Explanatory Answers?

To test my primary hypotheses, I compared the patterns of child responses following an adult explanation versus no explanation. Table 1 is arranged so that the child response categories where I hypothesized key contrasts are reported in the top section. Namely, I predicted that children would be more likely to agree and ask followup questions following explanations, whereas the responses of re-asking the original question and providing their own explanation were predicted to be more frequent following non-explanatory answers. Child response categories where I did not have predictions or that I did not expect to significantly differ between explanation and non- 
explanations are at the bottom of Table 1 . These categories provide additional information about the other ways children react to adult responses.

The proportions in Table 1 were calculated by dividing the frequency of each type of response (following an explanation or a non-explanation) by the total number of explanations or non-explanations received. An overall chi-square analysis across the 8 categories in Table 1 confirmed a significant difference in the pattern of child responses with relation to whether or not the child received an explanation, $X^{2}(7, N=3162)=$ 382.8, $p<.001$. Agreeing and follow-up questions were more frequent following adult explanations versus adult non-explanation responses (11.1\% vs. $6.3 \%, z=4.85, p<.001$, and $18.5 \%$ vs. $4.6 \%, z=12.81, p<.001$, respectively). Conversely, in conversations where children did not receive an explanation (compared to those in which they did receive an explanation), they were more likely to re-ask the original question (24.0\% vs. $9.4 \%, z=-10.20, p<.001)$, and to provide their own explanation $(10.7 \%$ vs. $1.0 \%, z=-$ 10.16, $p=.001$ ). When examined separately, all 6 children followed the same patterns in these four key categories (agreeing and follow-up questions were more frequent after explanations, and re-asking and providing own explanations were more frequent after non-explanations).

Note that these significant differences in the patterns of children's reactions following explanations versus non-explanations refute the hypothesis that children are simply trying to extend the conversation and that any adult response they get would be a satisfying one. In contrast, the presence or absence of explanatory content appears to be a key factor in how children react. 
With regard to the other categories, disagreeing was relatively infrequent, but when it did occur it was more frequent following adult explanations versus nonexplanatory responses (3.4\% vs. $1.6 \%, z=3.38, p<.001$, respectively). In conversations where children did not receive an explanation (compared to those in which they did receive an explanation), they were more likely to provide additional on-topic information (19.9\% vs. $15.3 \%, z=-3.21, p<.01)$. Children were not significantly more likely to change the topic following either an explanation or a non-explanatory answer $(20.7 \%$ vs. 17.3\%, $z=2.38$, n.s.). Finally, children were more likely to not respond at all following an explanation versus a non-explanation (20.5\% vs. $15.6 \%, z=3.50, p<.001)$. Are there Developmental Differences in Children's Patterns of Reactions?

Because these analyses collapsed across all child utterances, they raise the question whether these patterns of appropriate responses might be carried solely by the oldest children. However, even as 2-year-olds, these children's responses evidenced the same patterns following explanations and non-explanations. Data for the instances when 2-year-olds responded by agreeing did not reach significance, but were in the predicted direction, with a larger proportion of agreeing following explanations compared to nonexplanations (10.6\% vs. 8.1\%). As 2-year-olds, these children more frequently asked follow-up questions following adult explanations compared to non-explanatory adult responses $(20.5 \%$ vs. $2.3 \%, z=7.68, p<.001)$. Two-year-olds were significantly more likely to re-ask their original question following non-explanatory adult responses compared to explanatory responses $(34.3 \%$ vs. $12.2 \%, z=-6.36, p<.001)$. Two-yearolds’ provision of their own explanations could not be tested due to small frequencies; 
however, the nine times children did provide their own explanations at this age, they followed non-explanatory responses from adults.

Besides this examination of the youngest age, I also explored age trends. An overall chi-square analysis comparing the relative proportions of child responses at each age (2-, 3-, and 4-years-old) was significant, $X^{2}(14, N=3162)=133.3, p<.001$. To examine this overall finding further, age patterns were examined on a child-by-child basis to determine if there were any developmental patterns upheld by at least 5 of the 6 children for the 4 key categories (agrees, follow-up question, re-asks, or providing own explanation). There was one consistent developmental pattern in the overall relative frequencies of child response types over time. Providing his/her own explanation increased with age for 5 of the 6 children. Pair-wise z-scores showed a significant increase from age 2 to age $3(1.4 \%$ vs. $6.8 \%, z=-5.22, p<.001)$ and from age 3 to age 4 $(6.8 \%$ vs. $12.1 \%, z=-4.52, p<.001)$ in children’s frequency of providing their own explanations.

\section{Do Children Respond Differently to Different Types of Explanations?}

Child responses did not differ significantly based on the form of explanation (mechanism, prior causal event, consequence, current state of world, or other) voiced by the adult, $X^{2}(28, N=1150)=17.39$, n.s. Children responded to each type of explanation with a similar pattern of responses.

Are Children's Response Patterns Affected By the Length of the Adult Response?

Finally, I investigated the hypothesis that children's reactions could be based on the length of the adult response. In general, adult responses ranged from 1 word to 56 words in length, with a median length of 5 words. I excluded instances when children did 
not receive any adult response $(n=945)$ from analysis. Length was confounded with the type of adult response: explanations had a longer average length $(M=7.61$ words, $S D=$ 4.81) than non-explanatory answers $(M=4.89$ words, $S D=3.72)$. This was confirmed by a significant 2 x 2 chi-square, comparing explanations and non-explanatory answers with length, which was split into short (5 words or less) versus long (6 words or more), $X^{2}(1, N=2217)=158.8, p<.001$.

To attempt to disentangle the effects of length and explanatory response, I compared the relative proportions of child responses following explanations and nonexplanations within the short answers (5 words or less) and then separately within the long answers (6 words or more). For short adult responses, the overall chi-square was still significant, $X^{2}(7, N=1146)=158.1, p<.001$, so I then conducted $z$-tests to determine if there were significant differences in the key child response categories. Children were not significantly more likely to agree with short explanations compared to short non-explanations (12.0\% vs. $11.4 \%, z=0.31$, n.s.). However, children were significantly more likely to ask a follow-up question after receiving a short explanation compared to a short non-explanation $(18.8 \%$ vs. $3.3 \%, z=8.80, p<.001)$. Following short non-explanations, children were significantly more likely to re-ask their original question (18.6\% vs. $12.0 \%, z=-2.97, p<.01)$ and give their own explanation $(11.4 \%$ vs. $1.3 \%, z=-6.33, p<.001)$ than they were to short explanations. Thus, even within the shortest adult responses, children still recognized the difference between an explanation and a non-explanation, responding in meaningfully different ways to these two types of responses.

A similar pattern was found for long adult responses. The overall chi-square 
comparing the pattern of child responses following long explanations and long nonexplanatory answers was significant, $X^{2}(7, N=1071)=59.5, p<.001$. Z-tests for the four focal categories of child reaction showed two were significant and in the expected directions. Specifically, children were significantly more likely to ask a follow-up question after receiving a long explanation compared to a long non-explanation (18.4\% vs. $6.9 \%, z=5.05, p<.001)$. Conversely, following long non-explanations, children were significantly more likely to give their own explanation (5.8\% vs. $0.8 \%, z=-4.88, p$ $<$.001) than they were to long explanations.

\section{Discussion}

These results confirm the prediction that children respond differently and appropriately to explanatory versus non-explanatory answers to their questions. When asking why and how questions, young children are not merely trying to extend conversation with an adult, but instead appear to be actively seeking explanatory information. Thus, when preschool-aged children receive an explanation to these questions, they appear satisfied (as evidenced by their agreement), and in some cases are motivated to pursue new information on the same topic (by asking a follow-up question). In contrast, when children do not receive an explanation, they are persistent in re-asking for this information or in suggesting their own explanation. Evidence of these same response patterns was present even for the youngest children in the sample. Length of adult response also influenced children's reactions. But explanatory content, and not simply length alone, was an important factor. Thus, within the shortest adult responses, as well as within the longest ones, children still reacted differently and appropriately to explanations and non-explanations. 
Study 2 aims to replicate these patterns of child responses within an experimental format. Beyond replication, the experimental format provides the opportunity to address several challenges with the naturalistic data used in Study 1, namely small sample size and the confounding issue of length of adult responses. 


\section{CHAPTER III}

\section{Study 2: Experimental Study of Children's Responses Following Explanations versus Non-Explanatory Answers}

The general aim for Study 2 was to examine children's responses to explanations versus non-explanatory answers within an experimental context. Although conversational sequences were revealing in the naturalistic data, numerous utterances must be available from everyday conversation to accrue enough data for analysis. In Study 1 (as well as in Chouinard, 2007 and Hickling \& Wellman, 2001), this resulted in small sample sizes. An experimental situation can be structured to prompt children’s inquiries with higher frequency. Moreover, experimental contexts allow for experimental control. In particular, in the lab I could script adult responses, allowing for more controlled contrasts of how the child would respond to explanations versus nonexplanations. Scripted adult responses with specified topics for conversation also provided the advantage of avoiding confounds of various sorts that may exist in naturalistic data where conversational partners have complete freedom over the topic of discussion. In particular, it allowed us to disentangle length and explanation/nonexplanation in adult responses.

Thus the specific aims for this study were to devise situations and items where children's question-asking could be elicited and then to provide controlled adult responses to those questions. To achieve these aims, I devised a methodology inspired by research by Kemler Nelson, Egan, and Holt (2004). In their study, 2-, 3-, and 4-year-old 
children were encouraged to ask questions about unfamiliar artifacts. The procedure began with a short warm-up where a puppet modeled question-asking and then children were given opportunities to ask the researcher questions about 12 test objects. Using this methodology, on average 3-and 4-year-olds asked at least one question each about 10 or 11 of the 12 objects.

Kemler Nelson et al. (2004) focused on object-situations where children were likely to ask ambiguous questions (e.g., "What is it?”). For some children these ambiguous questions were answered with the object's name and for other children they were answered with the object's function. To assess children's satisfaction with the type of answer they received, Kemler Nelson et al. (2004) measured how often children followed up their original question with additional, often more specific/directed inquiries. In their research, children were more likely to ask additional questions when given a name for the object. In contrast, children asked fewer additional questions when given a function. The researchers interpreted this reaction as meaning that the children were seeking and thus were more satisfied with function information in comparison to name information.

In Study 2, incorporating similar techniques, I used a series of objects, storybooks, pictures, and short videos to elicit children's explanatory inquiries. The stimuli depicted surprising, unusual, or expectation-violating situations that had the potential to provoke requests for explanations, such as a story about a girl who pours ketchup on her ice cream or a video of a woman turning the lights off with her foot instead of her hand. Just as in Study 1, rather than being situated within a single domain (e.g., unfamiliar artifacts, biological phenomena, mechanical events, etc.), I included a 
variety of items, situations, and domains for events that might need to be explained (e.g., psychological motivations, physical consequences, biological phenomena). The key outcomes measured for this study, as in Study 1, concerned how the children reacted when the adult provided an explanation versus a non-explanatory response.

Initially, I hoped to create situations where the adult would provide explanatory and non-explanatory information only after the child participant asked a causal why or how question. However, in piloting testing, there were significant individual differences in how often children asked questions. Moreover, often it seemed that children were often requesting an explanation by using statements rather than articulating a specific causal question (e.g., saying "Hey, she used her foot!” when encountering the video of the woman turning off the light switch with her foot). Pragmatically, these statements operated as requests for the adult to explain what the child was noticing and commenting on. I refer to these types of statements as "requestive” statements, borrowing from language used by linguists to describe the illocutionary force or intended function behind speech acts that are formally statements, yet function as requests (see Searle, 1969). Based on this pilot testing, in the final procedure the signal for the adult to provide the explanatory or non-explanatory answer was when the child verbally acknowledged the unusual aspect of the stimulus, including cases when the child produced a causal question or an appropriate requestive statement or exclamation remarking on the oddity.

Predictions for the outcome of this study parallel and extend those for Study 1 regarding explanatory versus non-explanatory responses. Using the same logic as in Study 1, if children are actively seeking out explanatory knowledge, one would expect to find variation in the pattern of children's responses based on whether or not they have 
received an explanation. In particular, when children do not receive an explanation, I predicted signs of dissatisfaction and specifically that they would be more likely to re-ask their original question. When children do receive an explanation, I predicted that they would be more likely to show signs of satisfaction with the answer by agreeing or nodding their heads (a response I could now capture on videotape). In addition, following explanations, I predicted children would be more likely to ask an additional question that is different from the original question, but building on the same topic (a follow-up question).

\section{Method}

\section{Participants}

Participants were 42 preschool children from a Midwestern university city. The sample was recruited from university preschools that encourage active exploration and questioning. The community from which this sample was recruited is predominantly Caucasian, and highly-educated. There were 21 younger children (mean age $=3$ years, 11 months; $S D=2.76$ months; 11 girls, 10 boys) ranging from 3 years, 5 months to 4 years, 3 months of age and 21 older children (mean age $=4$ years, 9 months; $S D=3.60$ months; 7 girls, 14 boys) ranging from 4 years, 4 months to 5 years, 3 months of age. An additional three children were dropped from the final sample because they did not complete the study.

\section{Materials}

Materials included 4 objects, 4 storybooks, 4 pictures, and 4 short videos designed to create surprising, question-provoking situations. The objects included a box of crayons containing only one color of crayon (e.g., all red), a puzzle with a piece that did 
not fit, a hat with a hole in it, and a clam-shell toy cell phone that would not open. The storybooks described a child who poured orange juice on his cereal instead of milk, a girl who poured ketchup on her ice cream instead of chocolate sauce, a boy who wore a scarf and mittens to play outside on a warm day, and a girl who went to bed with her clothes and shoes on. The pictures depicted situations with one surprising feature; a picture of a bird's nest containing two baby birds and a turtle, an unusually small door, a normally dressed man wearing a clown nose, and a bed located outside of a house on the lawn. The videos presented short segments showing a person doing puzzling activities, including turning off a light with her foot, spinning while walking across a room, wearing a bucket instead of a hat, and jumping on her hat. To ensure the child had been able to see everything that happened in the video, the videos were each presented three times back to back.

Procedure

Children were tested individually in a quiet room at their school. The interaction was videotaped either by a separate researcher seated in the room holding the video camera, or by using a video camera attached to a tripod in view of the child.

The adult began by explaining, "I brought some toys from my house to show you today. These are my toys, so if you have any questions about them, you can ask me.” Next, a short warm-up activity was used to briefly model the question-asking conversational format and engage the child. The warm-up began with the adult introducing the child to a puppet named "Buggy." Buggy then answered two of the adult's questions about a toy car with an unusual hook attached to it. These questions included one non-causal question, "What is that?” and one causal why question, "Why 
does it have a hook on it?”

Participants were then presented with the objects, storybooks, pictures, and short videos. Each item was presented individually and the items were presented in the same order for all children. The adult presented each item with a short statement introducing it, without explicitly mentioning the unusual or surprising aspect of the item. For example, “This is my brand new hat,” or “Can you help me put this puzzle together?” If the child demonstrated recognition of the unusual aspect of the stimulus (including asking a causal why or how question or making a statement about the unusual aspect with a quizzical look or intonation), the researcher responded by providing either an explanation or a non-explanatory answer (alternating over trials).

Non-explanatory answers included four different types: restatement (e.g., "You're right, there is a turtle in that bird’s nest.”); normative (e.g., "People don’t usually wear red noses like that.”); descriptive (e.g., “That looks like vanilla ice cream.”); and personal reaction (e.g., “I like to put milk on my cereal.”). See Appendix B for list of explanations and non-explanatory answers used with each stimulus. These different types of nonexplanatory answers were modeled on some of the non-explanatory answers adults gave in Study 1. Using different types, rather than a single format, for these non-explanations created useful variation in that it reduces the predictability of what the adult will say in response to the child's inquiries.

As discussed for Study 1, there are alternative possibilities for why a child might respond to explanations and non-explanations differently (other than the presence versus absence of explanatory information). One possibility is that children might respond to differences in length between these two types of answers. In Study 2, however, the 
explanation and non-explanation for each item were created to be equal in word length. The average word length for explanations was 9 words and the average word length for non-explanations was 8.5 words. Another alternative possibility might be that children would respond to the presence of causal terms in the explanations that are absent from the non-explanations. To address this possibility, explanations were carefully worded to avoid using key causal terms such as "because” and "so” for all cases, with only one exception.

The adult paused to allow time for the child's response before moving on to the next item. In cases where the researcher had responded with a non-explanation and the child re-asked his or her original question (or continued to demonstrate curiosity about the unusual aspect of the item), the researcher provided the explanatory answer.

Children's responses to the adult's provision of an explanation versus a nonexplanation were coded from the videotaped interactions, using a coding system similar to the one used in Study 1, including the key categories:

a) Agreeing with the adult, including nodding head or saying “oh,”

For example: CHILD: “Why Cathy did that?” ADULT (explanation): “She thought it was chocolate syrup,” CHILD: “Oh, chocolate syrup.”

b) Asking a follow-up question,

For example: CHILD: “Why does he have his bed outside like this?” ADULT (explanation): “Tommy’s parents are painting his room,” CHILD: “And they-and do they want it to be a surprise?”

c) Re-asking the original question, and

For example: CHILD: “What were you doing?” ADULT (non-explanation): 
“People don’t usually jump on hats,” CHILD: "Why were you doing it?”

d) Providing own explanation.

For example: CHILD: "But why she has the bucket on her head?” ADULT (non-explanation): “Well she didn’t put the hat on her head,” CHILD:

“Because she didn’t see that hat?"

Additional categories were also included to provide additional information about the range of children's responses: e) smiles or laughs, f) disagrees with adult response, g) provides additional on-topic details, h) changes topic or asks for next item, and i) no response. The coding categories are detailed in Appendix C. Whether the child had used a statement or a question to acknowledge the unusual aspect of the stimulus was also coded.

Inter-rater reliability was established using randomly selected samples of $20 \%$ of the participants. Two persons independently coded the reliability sample and if a satisfactory level of agreement was not achieved, disagreements were discussed and an additional 20\% sample was selected for reliability coding. Overall across all 9 child response coding categories, there was $82 \%$ agreement, with a Kappa of .78. Reliability was also calculated for each child response coding category; percent agreement ranged from $93 \%$ to $98 \%$, with Kappas ranging from .73 to .88 . Because instances of children providing their own explanations were rare, reliability for this category was calculated using a separate $20 \%$ sample resulting in $99 \%$ agreement and a Kappa of .88. All of the Kappas for coding in this study fall within substantial (.61 to .80) levels of inter-rater reliability, and 44\% fall within near perfect (.81 and above) levels (Landis \& Koch, 1977). 


\section{Results}

Children were each presented with all 16 stimuli in individual sessions lasting 1525 minutes. Children asked an average of 4.6 questions total and made requestive statements about the unusual aspect of the stimulus an average of 7.7 times for a total of 12.3 "requests" for explanation. The adult researcher provided the child with an average of 6.1 explanations and 6.2 non-explanations in response to the child's requests about the unusual stimuli, in essence providing explanations and non-explanations each about 50\% of the time.

Do Children Respond Differently to Explanations versus Non-Explanatory Answers?

As in Study 1, if the purpose of children's causal questions is to actively seek out theory-building knowledge, one would expect to find variation in the pattern of children's responses based on whether or not they have received a causal explanation. Indeed, this variation was present as shown in Table 2, where again the more focal response categories (where I predicted key contrasts) are reported in the top section. Specifically, as in Study 1, I predicted that children would be more likely to agree and ask follow-up questions following explanations, whereas re-asking the original question and providing their own explanation were predicted to be more frequent following non-explanatory answers. Child response categories for which I did not have predictions or that I did not expect to differ significantly between explanation and non-explanations are in the lower portion of Table 2. These categories provide additional information about the ways in which children react to adult responses.

For the analyses, I calculated proportions for each child by dividing the frequency of each type of child reaction following an explanation by the number of explanations 
that child received. The same was done for child reactions following non-explanations, with the denominator being the number of non-explanations received by the child. An overall ANOVA indicated a significant difference in the patterns of child responses following explanations versus following non-explanations, $F(8,320)=11.95, p<.01$. Confirming the same patterns shown in Study 1, Bonferroni post-hoc comparisons showed that children were significantly more likely to agree, $p<.001$, or ask a follow-up question, $p<.001$, in response to explanations than to non-explanatory answers. Conversely, children were significantly more likely to respond by re-asking their question, $p<.001$, or by providing their own explanation, $p<.05$, following nonexplanations compared to explanations.

These patterns in children's responses were consistent across a majority of children in the sample. Of the 35 children who responded at least once by agreeing or nodding their heads, 29 did so more often following an explanation than following a nonexplanation, $p<.001$, binomial test. For follow-up questions, of the 24 children who asked at least one of these questions, 21 children did this more often in response to an explanation than in response to a non-explanation, $p<.001$, binomial test. All 20 of the children who responded at least once by re-asking their original question did so more often when they received a non-explanation as opposed to an explanation, $p<.001$, binomial test. Finally, 8 out of the 9 children who provided their own explanation at least once used this response more often following non-explanations than explanations, $p<$ .05 , binomial test.

With regard to the further coding categories, the videotaped data revealed that when children responded by smiling or laughing it was more likely to be in response to 
an explanation than in response to a non-explanation, $p<.01$. In both studies explicit disagreement with the adults' responses was very rare, but in this study, children were significantly more likely to disagree with non-explanations, $p<.01$, whereas in Study 1 this response was significantly more likely to follow an explanation. Finally, although the means are in the same direction in both studies, in this study, when children responded by providing additional on-topic supporting details or by changing the topic/asking for the next item or by giving no response, they were not significantly more likely to do these types of responses following either explanations or non-explanations. Whereas in Study 1, providing additional details was significantly more likely to follow a non-explanation, while giving no response was significantly more likely to follow an explanation.

I also compared the patterns of children's reactions following the four different types of non-explanatory answers (restatement, normative, descriptive and personal reaction) to confirm that they all functioned in the same way. Children's responses did not differ significantly based on the type of non-explanatory answer voiced by the adult, $F(24,528)=1.39, n . s$. Children responded to each type of non-explanation with a similar pattern of responses.

\section{Children's Use of Questions versus Statements to Request Explanations}

To confirm that children's use of requestive statements to conversationally point out the unusual aspect of the stimulus functioned as requests for explanations in the same way as did their questions, analyses were conducted to compare children’s response patterns following these two types of initial reactions. 
For the instances in which children acknowledged the unusual characteristic with a question, the same patterns of child reactions following explanations versus nonexplanations shown in the full sample were also demonstrated in this subset. As expected, when children asked a question initially they were more likely to agree/nod their heads, $t(41)=2.58, p<.05$, and ask a follow-up question, $t(41)=3.80, p<.001$, when they received an explanation than when they received a non-explanation. When children received a non-explanation in response to their question, they were more likely to re-ask their question, $t(41)=-4.32, p<.01$, or disagree, $t(41)=-2.41, p<.05$, in contrast to when they received an explanation. Children were not significantly more likely to provide their own explanation following a non-explanatory adult response versus an explanatory response.

Importantly, when children acknowledged the unusual aspect of the stimulus with a statement, they were also more likely to agree/nod their heads, $t(41)=3.19, p<.01$, and ask a follow-up question, $t(41)=2.95, p<.01$, in response to explanations compared to non-explanations. Also, (as with the instances when children voiced a question) when they used a statement to prompt an adult response they were also more likely to re-ask their question, $t(41)=-3.50, p<.01$, following a non-explanation than following an explanation. Although not significant, there was a trend for children to provide their own explanation more frequently following non-explanations compared to explanations, $t(41)$ $=-1.88, p<.10$.

Are there Developmental Differences in Children's Patterns of Reactions?

There were no significant main effects or interactions involving age. But to confirm that results hold for the younger children, separate analyses for this age group 
confirmed that they demonstrated the same pattern of reactions following explanations versus non-explanations. Specifically, just as in the entire data, even the youngest children were more likely to agree/nod their heads, $t(20)=2.43, p<.05$, and ask a follow-up question, $t(20)=2.24, p<.05$, in response to explanation than in response to a non-explanation. Children in the younger age group were also more likely to re-ask their original question following a non-explanation than following an explanation, $t(20)=$ -

$3.61, p<.01$. Although the younger children did not demonstrate significant differences in voicing their own explanations following explanations versus non explanations, this response did show a trend in the same direction as the general sample (with their own explanations more likely to follow non-explanations, $t(20)=-1.86, p<.10)$.

\section{Discussion}

These results further demonstrate that when asking causal questions (or using statements that point out a surprising feature) with adult conversational partners, young children are more satisfied with adult responses that provided a causal explanation compared to those that do not. In the cases when they do not get an explanation, even the youngest children continue to seek this causal information by re-asking their question. Additionally, in both this study and Study 1, children are significantly more likely to ask a follow-up question to their original inquiry when it was answered with an explanation than when it was not. This suggests that causal explanations may foster continued conversation and knowledge seeking.

Study 2 also yielded a promising experimental method, useable in further research, with several specific advantages. First, this methodology provides a means for eliciting frequent, relevant child responses in a half-hour session rather than hours of 
transcript. Second, scripting adult responses allowed for control over possible confounding factors such as length and the presence of causal vocabulary (words like "because" and "so"). My control of these factors means that the results from Study 2 cannot be due to length or the mere presence of causal words in adult responses. Children instead appear to be responding in organized, meaningful ways based on the presence or absence of explanatory content in the adult responses they receive.

General Discussion for Studies 1 and 2

Examining conversational exchanges, with a particular focus on children's reactions to the different types of information they get from adults in response their own requests, provides several important insights. First, the different patterns in children's reactions following explanatory versus non-explanatory information gives firm support for the hypothesis that young children are motivated to actively seek out causal information and are capable of using specific conversational strategies to obtain it. Second, when preschool children ask numerous “why?” questions, they are not merely trying to prolong conversation (as previously suspected by many parents and researchers alike). Upon receiving an explanation, but not otherwise, children often end their questioning and react with satisfaction.

The conclusions in these studies are especially strong because they converge across both naturalistic situations and conversations (Study 1) and more controlled laboratory situations and conversations (Study 2). With these comprehensive methods, I are not just measuring the causal knowledge children already have, but are assessing a socially-situated process by which they can obtain this knowledge within their everyday lives. Conversational interchange is surely not the only way children obtain causal 
information (consider e.g., direct instruction or first-hand observation), but children's requests within adult-child conversation are a frequently used and useful tool for their seeking out this knowledge. These child-adults exchanges prove to be similarly useful for investigators to specify exactly which knowledge the child wants to find out. (Complementing Harris and Koenig (2006)'s discussion of children learning from adult's testimony.)

These studies raise several questions for future research. First, there are the questions of what exactly constitutes a satisfying explanation for children and whether this changes developmentally. The explanations voiced by adults in Study 1 and scripted in Study 2 are generally relatively concise, and yet they are considered satisfying by preschool-aged children. Would briefer, or more detailed, explanations be similarly satisfying? This is importantly related to Keil and colleagues' arguments about the "shallows" of ordinary explanation (Mills \& Keil, 2004; Rozenblit \& Keil, 2002). Here, there is the further important question of whether adults' satisfaction with less-detailed versus more detailed explanations is the same as children's satisfaction with these explanations. The methodology created for Study 2 (i.e., the set of stimuli that reliably prompt children to voice questions and make inquiries) provides a means for potentially answering these questions. Studies 3 and 4 investigate the issues raised here by examining adults' and children's preferences for different types of explanations. 


\section{CHAPTER IV}

\section{Introduction: Adults' and Preschool Children's Preferences for Explanatory Detail}

In the previous two studies, I demonstrated that children react systematically differently based on whether they have received an explanation or not in response to their inquiries. This leads to additional intriguing questions about how children evaluate this explanatory information: Is any explanatory information good enough? Are some explanations better than others?

Intuitively, one would expect that differences in the structure or content of explanations could affect their appeal, making some explanations more satisfying than other explanations. For example, the factor of length was raised in Study 1; perhaps longer explanations are more satisfying, on average, because they contain more information, are more detailed, or are more specific in their content. However, one could imagine other, more meaningful differences in the content of explanations that might lead to some types of explanations being more satisfying than others. Although I did not find a difference between children's reactions to prior cause, consequence, mechanism, or state of the world explanations as I defined them in Study 1, other distinctions between different types of explanations may have an impact on children's (and adults') level of satisfaction. I begin by reviewing the literature addressing the issue of explanatory depth or detail and then provide examples from the large body of research that has studied different types of explanations. This serves to inform a research design I then use to 
examine first adults' and then children's satisfaction with and recall of explanations that differ in the amount of detail they provide.

\section{The Issue of Explanatory Depth}

Does adding detail to an explanation make it more satisfying? If so, what sort of details? How detailed are the explanations that adults and children possess and prefer? Keil and colleagues have found that both adults and children overestimate the amount of detail they are able to provide when asked to explain how an everyday mechanical device works (Mills \& Keil, 2004; Rozenblit \& Keil, 2002). In these studies, adults and elementary-school children are asked to rate their understanding of familiar mechanical devices both before and after a series of manipulations which include: writing a step-bystep explanation of how the device works, answering a diagnostic question about the mechanism, and reading an “expert” explanation. Adults, fourth-graders, and secondgraders show a similar pattern of re-evaluating their previous estimations of their own knowledge and lowering their ratings for how much they understand about the devices. In other words, at first, participants rate themselves as having a fairly good explanatory understanding of the devices, but after exposure to the different manipulations participants recognize how little they actually knew. Rozenblit and Keil (2002) dubbed this effect the "illusion of explanatory depth."

This research raises intriguing questions. For our everyday knowledge of the world, how much explanatory “depth,” completeness, or detail do we seek, obtain, and prefer? Do these preferences change when we are actively learning facts about a phenomenon or domain compared to when we are more passively gathering information through observation or instruction? Is it different for young children who are often just 
learning about phenomena and domains? One interpretation of the adults and children in Keil and colleagues' research is that they recognize the more detailed "expert" explanations as being better and this causes them to lower ratings of their own knowledge in comparison. In this way, they appear to indicate a preference for more detail. But if so, why do people often provide only superficial explanations? And is more detail always better? Keil's research tells us about adults' and children's abilities to evaluate explanations and the level of detail in the explanations they possess, but it does not tell us the amount of detail adults and children prefer or seek. In fact, one could take the opposing position that the “shallow” nature of adults' and children's explanatory knowledge suggests that they may prefer less detailed explanations and do not seek to obtain full, deep, detailed understanding of everyday causal mechanisms, but rather less detailed (even “shallow”) understanding (see Keil, 1998). This may be especially true for children who are developing knowledge in unfamiliar domains, as they build an abstract understanding before moving to a more concrete one (Simons \& Keil, 1995; Wellman \& Gelman, 1998).

Intuitively, detail and “depth” come in varying degrees or levels, and so people might prefer and seek explanations and understandings that are not "shallow," but are also not complete and fully detailed. After a point, deeper would not necessarily be better. Thus, one hypothesis is that adults or children may have some sense of an optimal level of detail; providing additional detail beyond this point results in an explanation becoming less satisfying (because it is seen as unnecessary). Within the context of explanation-seeking, adults' and children’s preferences for explanatory detail remains an open question. I investigate the three different possibilities raised here in Studies 3 and 4 
by comparing participants' reactions to explanations with little, more, and a lot more detail. However, it is also important to situate my research within a context of the previous work on children's preferences for different types of explanations.

\section{Children's Preferences for Different Types of Explanations}

One way to directly measure children's preferences for one type of explanation over another is to give children a description of a phenomenon and then ask them to choose the best/most plausible explanation from a set of choices. Past studies have used this forced-choice method, examining primarily two dimensions of explanations: modes of explanation for specific content areas and more general metacognitive criteria of explanations.

There is an extensive body of research looking at children's modes of explanation within specific domains including naïve psychology, naïve physics, and naïve biology. These types of forced-choice studies have often been done with the purpose of investigating the nature of children's understandings within a particular domain. One example of these studies is Hatano and Inagaki (1993). In this study, 6-year-olds, 8-yearolds, and adults were presented with a causal question about a biological process (e.g., "Why do we eat food every day?”) and then asked to pick the best explanation from three choices: an intentional explanation (e.g., "Because we want to eat tasty food"), a vitalistic explanation (e.g., "Because our stomach takes in vital power from the food"), and a mechanical explanation (e.g., "Because we take the food into our body after its form is changed in the stomach and bowels"). Six-year-olds chose the vitalistic explanations most often, whereas 8-year-olds and adults chose mechanical explanations most often. Studies like this one examining children's explanatory preferences within domains reveal 
that children tend to prefer modes of explanation that are appropriately matched with the domain of the phenomenon (Wellman \& Gelman, 1998). However, these studies do not tell us more generally (across domains) whether children prefer explanations of a particular form or level of detail.

Other research has focused on more domain-general properties of explanations. For example, Brewer, Chin, and Samarapungavan (1998) identified five qualities of everyday explanations (empirical accuracy, scope, consistency, simplicity, and plausibility), and Samarapungavan (1992) tested elementary-school children's sensitivity to some of these metacognitive criteria of explanations within a theory choice task. When children were asked to pick the correct mini-theory from two choices (one that demonstrated the particular metacognitive trait and one that did not), children as young as 7 years consistently selected choices that accounted for more observations over ones that accounted for fewer observations (range), choices that were consistent with evidence over those that were not consistent (empirical consistency), and choices that were internally consistent over those that contained contradictions (logical consistency). Preference for mini-theories that are not ad hoc over those that use ad hoc reasoning (i.e., theories that possessed extra assumptions that were not testable) was demonstrated by older children (11-year-olds) only.

In addition, recent work by Bonawitz and Lombrozo (2007) investigated children's preferences for simplicity and probability in causal explanations. In their research, like adults (Lombrozo, in press), 6-year-old participants also prefer simpler explanations that present a single cause for an event rather than two simultaneous causes (e.g., in explaining two missing muffins, children prefer the explanation of one bear 
eating both, rather than two bears each having one). Results were less clear with regard to plausibility.

Finally, it is important to mention that in addition to research studies using a forced-choice methodology, another common methodology has been to examine children's explanations as given in their own words. In a laboratory-based version of this methodology, investigators ask children a causal question about a phenomenon and then children's explanations are recorded, transcribed, and coded for the presence of different types of explanations. An excellent example of this methodology is Au and Romo’s (1999) examination of the causal mechanisms present in children’s explanations for biological phenomena. Examination of children's explanations in their own words has also been conducted within naturalistic contexts, as in Hickling and Wellman (2001).

The current research takes a new approach to examining children’s and adults explanatory preferences. For children, as in Study 2, I created situations where children were likely to request explanatory information and then I systematically varied the type of answer given by the adult to see if children will react differently to the different types of answers they receive (which include, in this study, 3 different types or levels of explanation). This methodology provides information about children's preferences in situations where they are actively seeking explanatory information and initiating the conversation (in contrast to the researcher-initiated questioning used in much of the previous research). It is also important to note that all the previous studies looking at children's preferences for different types of explanation focus exclusively on older, school-age children. The methodology used in this research allows for the examination of younger, preschool-aged children’s explanation preferences. 
More specifically, my aim for Studies 3 and 4 was to contribute to the literature concerning explanation preferences by exploring how the amount of detail affects adults' and children's satisfaction with the explanations they receive. I created three levels of explanation, where a level-1 explanation provides very little detail, but still gives enough information to be considered an explanation. For example, given the question: "Why did she pour ketchup on her ice cream?” a level-1 or low-detail explanation might be, "It was a mistake.” Level-2 medium-detail explanations added more detail to the explanation such as, "It was a mistake because she thought it was chocolate in the bottle." Finally, to create the level-3 or high-detail explanations, I added even more detail to the explanation, such as, "It was a mistake because she thought it was chocolate in the bottle because the ketchup bottle and the chocolate bottle look the same.”

There are four possible patterns for how participants could react differently to these three levels of explanation. One possibility is that adults and perhaps especially children could react as if any explanation is good enough. In other words, they would be satisfied with any explanation (as opposed to a non-explanation), regardless of its level of detail. Another possibility would be that participants may believe that more detail is better. In this case, participants' satisfaction should increase with the amount of detail provided. (Keil's research might suggest this possibility). A third possibility would be that adults and again especially children might prefer the least detailed explanations because more detailed explanations are increasingly overwhelming or boring. In this case, their satisfaction should decrease with increasing detail in the explanation. A final possibility, which I favor, is that children and adults may prefer the explanations that provide a medium level of detail (level-2 explanations in my scheme). In this case, 
participants would be less satisfied with the low detail explanations (level-1) because they do not provide enough information and less satisfied with the high level detail explanations (level-3) because they provide too much information. 


\section{CHAPTER V}

\section{Study 3: Adult Ratings of Explanations and Non-Explanations that Vary in Explanatory Detail}

Studies 3 and 4 examined participants' reactions to the three different levels of explanations and non-explanatory answers. Study 3 allowed us to test my initial intuitions with adults to see if, when I provided three different levels of explanatory detail, adults would distinguish between them and potentially find one level optimally satisfying. Additionally, Study 3 provided the adult information needed to design Study 4 with children.

In this study, adult participants were presented with pictures that depict surprising, unusual, or expectation-violating situations, with descriptive statements below the pictures and a target why question asking about the unusual aspect of the situation. Participants were asked to rate an answer to the target why question both with regard to how satisfying each answer was and whether the answer provided an explanation to the question. As a manipulation check, the participants also rated the relative length of the answers. There were four possible types of answers for each target why question, including one non-explanatory answer and three different explanations.

As outlined earlier, the explanations used in this study varied in the amount and type of detail they provided, and in their length in words. The aim was to contrast three levels of explanations: a) relatively shallow explanations with the least amount of detail, b) explanations with an intermediate level of detail, and c) longer explanations that 
provided the most degree of detail. The goal for Study 3 was to see if these different explanations would yield consistent patterns between the amount of detail provided and adults' ratings of their satisfaction with each answer. I hypothesized that there would be strong distinctions between the ratings of satisfaction for the explanations versus the nonexplanatory answers. Additionally, I hypothesized that the amount of detail and degree of satisfaction might be somewhat independent of one another. More specifically, I expected that for adults' satisfaction would increase from the level-1 explanations to the level-2 explanations, but that the level-3 explanations might not be considerably more satisfying than the level-2 explanations because the additional detail in the level-3 explanations might be considered excessive.

Beyond providing background information, refined materials, and preliminary insights for Study 4, this study also provided a measure of the endpoint for possible developmental changes in preferences for different types of explanations. It is possible that children may have a different view of what constitutes a satisfying explanation, preferring either a shorter, simpler explanation or (conversely) the maximal amount of detail. Although the measures in the two studies (3 and 4) are different, the combined data provided an initial developmental comparison between adults' ratings (in Study 3 and children's reactions (in Study 4) to these different explanations.

\section{Method}

\section{Participants}

The sample included 64 adults (mean age $=18.73$ years old, 30 females, 34 males). Participants were recruited using the undergraduate psychology subject pool at a Midwestern university. 


\section{Materials}

Participants were given a packet of pictures depicting 16 unusual, questionprovoking objects or situations. These were amended/expanded versions of the same stimuli used in Study 2. Short written descriptions were included with each picture or set of pictures. Following each description was a specific why question that targeted the unusual aspect of each object/situation depicted. Following the target question was a candidate answer. These answers were one of four possible answers for each item (including three different explanations and one non-explanatory answer). The three explanations differed in terms of how much detail they provided. The non-explanation was included as a contrast to the explanations, similar to the comparison of explanations and non-explanations in Study 2.

For example, participants saw a photo of a hat with a hole cut in it (a picture of item 3 in Study 2). Written below this picture was the description, "This hat has a hole in it” and the target question, "Why does this have a hole in it?" Below that participants saw one of four answers:

Explanation Level-1: "The owner wanted it that way." (low level of detail; minimal explanation)

Explanation Level-2: "The owner wanted it that way so her ponytail could fit through the hole." (medium level of detail)

Explanation Level-3: "The owner wanted it that way so her ponytail could fit through the hole, so she cut a hole in it with her scissors." (high level of detail) Non-Explanation: "Hats don’t usually have holes in them."

Participants saw only one answer per item; the different answers for each item 
were counter-balanced between subjects. Across their 16 items, participants saw four of each type of answer (4 level-1 explanations, 4 level-2 explanations, 4 level-3 explanations, and 4 non-explanations). The items and answers and their presentation orders were scrambled so that types of answers were mixed across items for different subjects and both the items and the type of answer were not presented in any predictable order. For a complete list of explanations and non-explanatory answers used with each item, see Appendix D.

Procedure

Ratings. Participants were tested in groups in a quiet room on campus. They went through the packet of stimuli three times to rate each answer on the three different scales. Participants were asked to rate: whether or not the answer provided an explanation to the question ("yes" or "no"), their satisfaction with each answer (on a scale of 1-6, ranging from "not at all satisfying" to "very satisfying"), and their estimation of the length of each answer (on a scale of 1-6, ranging from "short" to "long"). The order in which participants rated the answers on these three dimensions was counter-balanced between subjects.

Recall. I included a recall task following the ratings to examine in a more exploratory fashion how well the participants remembered the answers they were presented. Particularly, I was interested in knowing which parts of the explanations they found to be the most salient or memorable. My reasoning was that the explanations might be better remembered than the non-explanations. Perhaps, even the level-1 explanatory information would be better recalled than the non-explanations. In addition, between the 3 levels of explanation, my expectation was that the level-2 explanations 
might be the most frequently recalled because they represent an optimal amount of detail.

To assess recall, after finishing the ratings, participants completed a distraction task (a page of multi-digit multiplication problems) lasting approximately 4-5 minutes, in order to prevent rehearsal of the explanations provided in the booklets. Participants were then given a packet containing black and white copies of all the picture stimuli (including the descriptions and target questions). Participants were instructed to "Please recall the answers that were provided earlier as accurately as possible,” and asked to write down what they remembered for each item. Items within the recall packet were not presented in the same order in which participants originally saw the stimuli (the items in the packets followed a standard order across participants).

Recall coding. Each response was scored based on the degree to which the content of the recalled answer matched the content of the 4 different types of scripted answers. Answers were broken up into segments based on the content added at each level of explanation. For example, for the item where there was a puzzle with piece that does not fit:

The level-1 explanation was: "This piece is too tall."

The level-2 explanation was: "This piece is too tall because two puzzles got mixed up.” The level-3 explanation was: "This piece is too tall because two puzzles got mixed up and this piece goes to a different puzzle.”

Thus, there were 3 segments that were scored as present or absent for any participants' recall for this item and the answer they received:

The E1 segment: "The piece is too tall"

The E2 segment: "Because two puzzles got mixed up" 
The E3 segment: “This piece goes to a different puzzle”

Each segment was given a score of either 1 (the information was present) or 0 (the information was not present). The non-explanations (e.g., “All the other pieces fit in this puzzle.”) were also scored 1 or 0 . The non-explanations were not broken up into segments because they were presented in only one form.

To get credit for a segment, the participant did not need to recall the segment verbatim, but just needed to get the gist (the underlined portions of the coding scheme, see Appendix E). For some of the segments, there were several ways the participant could get credit (symbolized by multiple segments being underlined in the Appendix). The coding scheme also included a list of common synonyms that received credit.

Inter-rater reliability was established using a randomly selected sample of $20 \%$ of the data. Two persons independently coded the reliability sample with $99 \%$ agreement and a kappa of .98 overall. Reliability was also calculated for each different segment type (E1, E2, E3, and NE); agreement ranged from 95\% to 98\%, with Kappas ranging from .64 to .84. All of the Kappas for this coding fall within substantial (.61 to .80) levels of inter-rater reliability, and 50\% fall within near perfect (.81 and above) levels (Landis \& Koch, 1977).

\section{Results}

\section{Explanations versus Non-Explanations}

First, I compared whether participants’ ratings distinguished between the explanatory and non-explanatory answers by averaging ratings across the three different types of explanations and comparing those averages with participants' average ratings for the non-explanatory items. In response to the question of whether the answer provided 
an explanation, participants said "yes" for explanatory answers 92.5\% of the time, whereas they said "yes" to non-explanatory answers only $4.1 \%$ of the time, $t(66)=$ 52.04, $p<.001$. Participants also rated the explanations as significantly more satisfying $(M=3.88$ out of 6$)$ than the non-explanatory answers $(M=1.56), t(66)=16.78, p<$ .001 .

Selection of Non-Explanatory Items

I next examined the patterns in participants' satisfaction ratings across the 3 different explanation types and non-explanations averaged across all 16 items. An overall ANOVA indicated a significant difference in adults' ratings of satisfaction, $F$ (3, 198) $=131.63, p<.001$. Bonferroni post-hoc tests yielded two general patterns in the data: (a) all three types of explanations (level-1, level-2, and level-3) were more satisfying than the non-explanations, all $p<.001$, (b) ratings of satisfaction increased from the level-1 to the level-2 explanations, $p<.001$, and (c) ratings of satisfaction between the level-2 and the level-3 explanations were not significantly different $(p>.5)$. When examined individually, the majority of the items (10 out of 16) followed all three of these patterns.

Because this was the modal and predominant pattern for adults, in order to best design Study 4, I selected a sub-sample of the most effective items (items that best fit the modal patterns for adults) for future use with children. For the explanatory items, I retained the 10 that fit the modal pattern exactly and the 2 others that most closely conformed to that pattern. The remaining four items were became the non-explanatory items for use with the children (children would all receive a non-explanatory response to these items) in Study 4. To allow for the clearest comparisons between the adult and 
child data, I report below results for adults that incorporate this decision, focusing on the explanatory data for 12 items and non-explanatory data from 4 items.

Due to the nature of the counterbalancing of different types of answers with the different items, 24 of the adult participants did not receive a non-explanation for one of the four target NE items leaving 43 participants for these analyses. To assure that the dropped data (the 24 participants' ratings of the level-1, level-2, and level-3 explanations they received) were not systematically different from the data from the other 43 participants, I conducted ANOVAs comparing these two groups. For all three ratings (whether the answer was an explanation, satisfaction, or length), there were no significant differences between ratings from the two groups.

I also confirmed the results comparing explanations (collapsed across levels) with non-explanations for these 43 participants. As in the larger sample, participants in this sub-sample were significantly more likely to say that the explanations (collapsed across levels) provided an explanatory answer compared to the non-explanations (94.3\% versus 7.8\%), $t(42)=21.73, p<.001$. They also rated the explanations as significantly more satisfying than the non-explanatory answers (4.00 versus 1.76), $t(42)=8.61, p<.001$. Identifying Answers as Explanations

Table 3 presents the ratings data. Paralleling the results with all the items and participants, an overall ANOVA indicated a significant difference in adults' identification of the four different types of answers (level-1 explanations, level-2 explanations, level-3 explanations, and non-explanations) as explanations, $F(3,126)=297.5, p<.001$. Bonferroni post-hoc tests showed that, compared with non-explanations, adults were significantly more likely to say that level-1 explanations $(p<.001)$, level-2 explanations 
( $p<.001$ ), and level-3 explanations $(p<.001)$ were explanations. Comparing within the different types of explanations, participants distinguished both level-2 $(p<.001)$ and level-3 explanations $(p<.01)$ from the less-detailed, level-1 explanations (i.e., level-2 and level-3 explanations were more often rated as explanations), but made no significant distinction between the explanatory value of level-2 and level-3 explanatory answers ( $p=$ 1.0). These two types of explanations were considered equivalent on this scale. Satisfaction with the Different Explanations and Non-Explanatory Answers

An overall ANOVA indicated a significant difference in adults' ratings of satisfaction with the four different types of answers (level-1 explanations, level-2 explanations, level-3 explanations, and non-explanations), $F(3,126)=42.92, p<.001$. Bonferroni post-hoc tests showed that adults were significantly more satisfied with level1 explanations $(p<.001)$, level-2 explanations $(p<.001)$, and level-3 explanations ( $p<$ .001) compared to non-explanations. Further, participants rated level-2 $(p<.01)$ and level-3 explanations $(p<.05)$ as more satisfying than the level-1 explanations. Again, there was no significant difference between participants' ratings of their satisfaction with level-2 and level-3 explanations ( $p=1.0)$. Ratings of Length

An overall ANOVA indicated a significant difference in adults' ratings of the length of the four different types of answers (level-1 explanations, level-2 explanations, level-3 explanations, and non-explanations), $F(3,126)=382.7, p<.001$. Bonferroni post-hoc comparisons showed that adult's ratings of length were significantly different for each answer type ( $p<.001$ ), with level-1 explanations being the shortest, followed by non-explanations, level-2 explanations, and finally, level-3 explanations being the 
longest. Thus adults were sensitive to differences among all three levels (including level2 versus level-3) in terms of their length although they never saw more than one explanation at a time.

\section{Adults' Recall of the Different Explanations and Non-Explanatory Answers}

Due to a change in procedure mid-way through data collection, the recall data are limited to 49 of the 64 adult participants. As with the rating data, when I focused exclusively on the items I used with children in Study 4, there was a sub-sample of adults who were not asked to recall one of the four target NE items. Therefore I focused on the 33 participants who received at least one of the four NE items, when comparing nonexplanation recall with recall for the different explanations. To assure that the dropped data (the 16 participants' recall of the explanatory segments they received) were not systematically different from the data from the other 33 participants, I conducted an ANOVA comparing these two groups. There was no significant difference between the two groups.

Table 4 presents the percentage of the time adults recalled the explanatory segments and non-explanations. The table is organized with the different types or levels of explanation in the rows and the segments that make up each level of explanation in the first three columns. As noted previously, the more detailed levels of explanation include the explanatory information/segments from the less detailed explanations (e.g., level-3 explanations include the level-2 and level-1 explanations).

To analyze these data, first I examined whether participants recalled explanatory information better than non-explanatory information. I compared participants' recall of the low detail explanations (containing only the E1 segment), medium detail explanations 
(averaging across the E1 and E2 segments, where participants could remember the E1 segment, the E2 segment or both segments), and high detail explanations (averaging across the E1, E2, and E3 segments, where the participant could remember the E1, E2 or E3 segment or any combination thereof) with their recall of the non-explanatory answers. In Table 4 this corresponds to a comparison between the fourth and fifth columns. None of these paired t-tests were significant.

Next, I conducted a series of planned comparisons to examine participants' recall of the different explanatory segments within the 3 types of explanations. As shown in the first and fourth row of Table 4, in general, adult participants were nearly perfect in recalling the shorter answers (level-1 explanations and non-explanations), regardless of the explanatory content. However, examining participants' recall of the different explanatory segments within the longer level-2 and level-3 explanations revealed that E2 segments were recalled significantly better than E1 segments within both level-2 explanations, $t(48)=-4.79, p<.001$, and level-3 explanations, $t(48)=-4.49, p<.001$. This can be seen by comparing across the second and third rows in Table 4. (There was no significant difference between participants' recall of E2 and E3 segments within level3 explanations.)

As previously mentioned, adult participants' recall of E1 segments was nearly perfect when these were the only information provided (in level-1 explanations). In comparison, and as shown in the first column in Table 4, the recall of these segments significantly dropped when included in level-2 explanations, $t(48)=5.25, p<.001$, and when included in level-3 explanations, $t(48)=6.28, p<.001$ (comparing recall within level-1 explanations to that within level-2 and level-3 explanations, respectively). 
Within level-3 explanations (the third row in Table 4), participants’ recall of E1 segments was also significantly worse than their recall of the E3 segments, $t(48)=-3.19$, $p<.01$. This suggests that E1 information was not as salient when competing with the presence of E2 detail.

Contrary to my prediction, explanations were not recalled more often than nonexplanations. Essentially, adults recalled all the answers they received at very high levels, with even the non-explanations recalled $87.4 \%$ of the time.

\section{Discussion}

In Study 3, results from the ratings show that, for adults, there are meaningful distinctions between the length of an explanation and the satisfactory nature of its content. More is not necessarily better. The level-1 explanations, though short (like the non-explanations), were still judged to be explanations the majority of the time and were also significantly more satisfying than the non-explanatory answers. Adding some detail made the level-2 explanations more likely to be judged as explanations, more satisfying, and in recall more accurately remembered. However, the additional detail present in the level-3 explanations did not significantly increase participants' satisfaction with these explanations. These results support my initial hypothesis that adults would have a preferred level of explanatory detail (level-2), one which includes enough detail to be satisfactorily explanative, but not so much detail as to become seemingly redundant, trivial, or unnecessary.

Beyond these substantive findings, Study 2 allowed us to identify a set of items and explanations that yield a clear pattern of results with the adults. In Study 4, I use 
these items with children to see how they react. The adults' data in Study 3 thus also provide a developmental endpoint to compare to the data collected with those children. 


\section{CHAPTER VI}

\section{Study 4: Experimental Study of Children's Satisfaction with Different Levels of Explanatory Detail}

Study 4 combines the methodology from Study 2 (question-provoking stimuli with scripted adult responses) with the different levels of explanations used in Study 3. My aims were to see if children, within a conversational context, would react differently to explanations that vary in their length and level of detail, and to see if children would show the same patterns as adults in their recall of the different explanatory segments.

More specifically, Study 4 followed the same general logic used and validated in the prior child studies (Studies 1 and 2), measuring children's satisfaction with different adult answers by examining their conversational responses to these adult answers. As before, I expected that when children are dissatisfied with the answer provided by the adult (e.g., when they receive non-explanations), they should be more likely to re-ask their original question or to provide their own explanation. In cases where children are satisfied (e.g. when they receive explanations), they should be more likely to agree with the answer or to continue the conversation with a new follow-up question.

Beyond children's responses to explanations versus non-explanations, my special focus here is their responses to the different levels of explanation. As outlined in Study 3, I consider four possible patterns for how children could respond differently to these different sorts of explanations. One possibility is that children could react as if any explanation is good enough. In other words, children would be satisfied with any 
explanation (as opposed to a non-explanation), regardless of its level of detail. Although this was not true of adults, it remains a distinct possibility for young, preschool children. Another possibility would be that children may believe that more detail is better. In this case, children's satisfaction should increase with the amount of detail provided. A third possibility would be that children might prefer the least detailed explanations because more detailed explanations are increasingly overwhelming or boring. In this case, children's satisfaction should decrease with increasing detail in the explanation. Again this was not true for adults, but could be for children who might at first prefer more general, less detailed levels of knowledge (see Wellman \& Gelman 1998; Mandler 1988). A final possibility would be that children, like adults in Study 3, might prefer the level-2 explanations, those that provide that provide a medium level of detail. They would be less satisfied with the low detail explanations (level-1) because they do not provide enough information and less satisfied with the high level detail explanations (level-3) because they provide too much information.

Although the recall portion of Study 3 was less informative (because adult recall was very high for all answers) Study 4 also included a portion that measured children's recall of the different answers they have received. I reasoned that this measure might be more informative with children whose recall would probably be less at ceiling and thus more differentiated and potentially more likely to include informative “errors.” So, after seeing all of the stimuli with the adult researcher as their conversational partner, the child participated in a short distraction task, then the adult asked him or her to recall the answers for half of the items (with items chosen to provide a balanced variety of explanatory and non-explanatory answers). Recall data provide an opportunity to 
measure which parts of the explanations are the most remembered or salient in children's memories. In addition, children’s recall when they received only a non-explanatory answer presented an opportunity to see if children would construct an explanation for the items on which they actually did not receive one. If so, this would be further indication of children's drive for explanation, a drive potentially strong enough to influence the child's memory. The recall task could therefore potentially work as an assessment of constructive memory processes, similar to Signorella and Liben’s (1984) work showing that children's memory was better for schema consistent material and that memory errors were most often the result of transforming inconsistent material into schema consistent material.

\section{Method}

\section{Participants}

Sixty-nine 4-year-olds $(N=36$; mean age $=54.82$ months, $S D=3.57$ months; 17 girls, 19 boys) and 5-year-olds $(N=33$; mean age $=63.32$ months, $S D=2.93$ months; 12 girls, 21 boys) participated. They were recruited from preschools located in a Midwestern university city and a smaller west-coast town, and the setting within the preschools is one in which active exploration and questioning are encouraged. The communities from which this sample was recruited are predominantly Caucasian, with mid- to high-level SES.

\section{Materials}

Materials consisted of the same set of 4 objects, 4 storybooks, 4 pictures, and 4 short videos that were used in Study 2.

\section{Procedure}


Children were tested individually by an adult interviewer in a quiet room at their school. The interaction was videotaped using a camera in view of the child. The researcher began the session with the same warm-up activity (with "Buggy” the puppet) used in Study 2. Participants were then presented with the objects, storybooks, pictures, and short videos. Each item was presented individually and the items were presented in the same order for all children. The ordering and presentation of the items was the same as in Study 2, with one exception. I began the session with an explanation item (the crayons) rather than the puzzle (which in this study was a non-explanation item).

As in Study 2, the adult presented each item with a short statement introducing the item, without explicitly mentioning the unusual or surprising aspect of the item. For example, “This is my brand new hat," or "Can you help me put this puzzle together?” When the child demonstrated recognition of the unusual aspect of the stimulus (including asking a causal why or how question or making a statement about the unusual aspect with a quizzical look or intonation), the researcher responded by giving one of the three types of explanations or a non-explanatory answer. For example, the three levels of explanation for the video of a girl turning off the lights with her foot were: Explanation Level-1: "She didn’t want to use her hands." (low level of detail; minimal explanation)

Explanation Level-2: "She didn’t want to use her hands because they were sticky." (medium level of detail)

Explanation Level-3: "She didn’t want to use her hands because they were sticky because some jelly squished out of her sandwich." (high level of detail)

The explanations used in this study are essentially identical to the ones used in 
Study 3 (or only slightly amended in a few cases to be more child-friendly), to allow adult-child comparison. The three different levels of explanation were varied across 12 of the 16 items using a repeated sequence that varied across children (e.g., level-3, then level-1, then level-2; or level-1, then level-3, then level-2; etc.) with the goal that children received an equal number of each type. For the other four items, the adult provided a non-explanation. The same four items were always non-explanations across all the children and were spaced evenly across the items presented (i.e., the fourth item, the eighth item, the twelfth item, and the sixteenth item). The non-explanatory answers included restatements (e.g., "All the other pieces fit in this puzzle”); normative descriptions (e.g., "People don’t usually jump on hats”); or descriptive details (e.g., “That bed is very comfortable”).

After giving the response, the adult paused to allow time for the child's reaction before moving on to the next item. In cases where the researcher had responded with a non-explanation and the child re-asked his or her original question (or continued to demonstrate curiosity about the unusual aspect of the item), the researcher avoided providing any additional information and answered the child by saying, "That's a good question. Would you like to see the next thing I brought?” This was done to avoid contaminating children's recall of the scripted responses at the end of the study. In preparation for the recall task at the end of the procedure, the adult researcher made sure that the child heard at least two types of each response (2 low-detail explanations, 2 medium-detail explanations, 2 high-detail explanations, and 2 nonexplanations). This required that the child inquire about at least half of the sixteen items. On each item, if the child did not verbalize a request for an explanation, the researcher 
prompted the child to notice and verbalize an acknowledgement of the unusual aspect of the stimulus by asking the child questions like, “Is there anything funny about this?” or “Is there anything you want to ask about this?” The conversation between the child and researcher was videotaped and transcribed.

\section{Coding}

The children's responses were coded into one of ten categories, using the same coding system as was used in Study 2. The four key categories again were:

a) Agreeing with the adult, including nodding head or saying “oh,” For example: CHILD: "She turning off the lights with, with her foot," ADULT (level-2 explanation): "She didn’t want to use her hands because they were sticky,” CHILD: “Oh.”

b) Asking a follow-up question,

For example: CHILD: “Does this open?” ADULT (level-1 explanation): “It’s stuck,” CHILD: “How’d it get stuck?”

c) Re-asking the original question, and

For example: CHILD: “Why’s his bed outside?” ADULT (non-explanation):

“That bed is very comfortable,” CHILD: "But why is it outside?”

d) Providing own explanation.

For example: CHILD: “Why'd she do that?” ADULT (non-explanation): “People don’t usually jump on hats,” CHILD: “Maybe she didn’t like that hat.”

Additional categories were also included to provide additional information about the range of children's responses: e) smiles or laughs, f) disagrees with adult response, g) 
provides additional on-topic details, h) changes topic or asks for next item, and i) no response. The coding categories are detailed in Appendix F. Whether the child had used a question or a requestive statement to acknowledge the unusual aspect of the stimulus was also coded.

Overall across all 9 child response coding categories, there was 86\% agreement, with a Kappa of .80. Reliability was also calculated for each child response coding category; percent agreement ranged from 93\% to 99\%, with Kappas ranging from .60 to .87. Because instances of children providing their own explanations were rare, reliability for this category was calculated using a separate $20 \%$ sample resulting in $99 \%$ agreement and a Kappa of .72. All of the Kappas for coding in this study fall within substantial (.61 to .80) levels of inter-rater reliability, and 33\% fall within near perfect (.81 and above) levels (Landis \& Koch, 1977).

Recall

As in Study 3, I also included a recall task at the end of the procedure to measure how much of the answers the participants accurately remembered. After finishing with the 16 stimuli, the researcher engaged the child in a 4-minute distraction task which involved the child looking for objects hidden in pictures (none overlapping with the test items). The researcher then asked the child about eight of the test items, using a small color picture of each item and a short statement to remind the child of the unusual aspect of the item (e.g., “Remember these crayons were all red.”). Then the researcher asked the child to recall the answer she had given for that item, (e.g., "Do you remember what I said about why they were all red?”). The eight items the researcher asked the child about included two of each type of explanation and two non-explanations. The researcher also 
tried to include items for which the child had asked a question initially, as opposed to those items where the child had used a statement to request an explanation or where the researcher had to point out the unusual aspect of the stimulus.

My predictions for the children were the same as those I had for the adult in advance of Study 3. In general, I predicted that children would remember the explanations better than the non-explanations. Again, I predicted that even the low-detail level-1 explanations would be better recalled than the non-explanations. For the level-2 and level-3 explanations, my prediction was that children, like the adults in Study 4, would recall the E2 segments more frequently than the other explanatory segments. As mentioned in the introduction for this study, I was also interested to see whether child participants would alter the non-explanatory answers they were given to be explanatory.

Recall coding. The children's recalled answers were videotaped and transcribed. As was done with the adults' answers in Study 3, the children's answers were coded for the presence/absence of different segments of the answers provided by the researcher. The same coding scheme was used across both Study 3 and Study 4 (see Appendix E), with the same guidelines and standards being applied to both adult and child answers. Inter-rater reliability for the child recall coding was established using randomly selected samples of $20 \%$ of the data. Two persons independently coded the reliability sample and if a satisfactory level of agreement was not achieved, disagreements were discussed and an additional 20\% sample was selected for reliability coding. Overall, the inter-rater reliability reached 95\% agreement, with a kappa of .80. Reliability was also calculated for each different segment type (E1, E2, E3 and NE); agreement ranged from $96 \%$ to $100 \%$, with Kappas ranging from .78 to 1.00. All of the Kappas for this coding 
fall within substantial (.61 to .80) levels of inter-rater reliability, and 75\% fall within near perfect (.81 and above) levels (Landis \& Koch, 1977).

Results

Children were each presented with all 16 stimuli in individual sessions lasting 1520 minutes. Children asked an average of 3.88 questions and made requestive statements about the unusual aspect of the stimulus an average of 11.75 times for a total of 15.63 “requests" for explanation. The adult researcher provided the child with an average of 3.94 level-1 explanations, 3.87 level-2 explanations, 3.93 level-3 explanations, and 3.90 non-explanations in response to the child's requests about the unusual stimuli, thus providing the four different answers each about $25 \%$ of the time.

Do Children Respond Differently to Explanations versus Non-Explanatory Answers?

As in Studies 1 and 2, if the purpose of children's causal questions is to actively seek explanatory knowledge, one would expect to find variation in the pattern of children's responses based on whether or not they have received a causal explanation. I first aimed to replicate their responses to explanations versus non-explanations in this study. Specifically, as in Studies 1 and 2, I predicted that children would be more likely to agree and ask follow-up questions following explanations, whereas re-asking the original question and providing their own explanation were predicted to be more frequent following non-explanatory answers.

To analyze these data, I calculated proportions for each child by dividing the frequency of each type of child reaction following an explanation by the number of explanations that that child received. The same was done for child reactions following non-explanations, with the denominator being the number of non-explanations received 
by the child. An overall ANOVA indicated a significant difference in the patterns of child responses following explanations versus following non-explanations, $F(8,544)=$ 14.06, $p<.001$. Confirming the same patterns as were shown in Study 1 and in Study 2, Bonferroni post-hoc comparisons showed that children were significantly more likely to agree, $p<.05$, or ask a follow-up question, $p<.001$, in response to explanations than to non-explanatory answers. Conversely, children were significantly more likely to respond by re-asking their question, $p<.001$, or by providing their own explanation, $p<.01$, following non-explanations compared to explanations.

As in Study 2, these patterns in children's responses were consistent across a majority of children in Study 4. Of the 47 children who responded at least once by agreeing or nodding their heads, 32 did so more often following an explanation than following a non-explanation, $p<.05$, binomial test. For follow-up questions, of the 41 children who asked at least one of these questions, 37 children did this more often in response to an explanation than in response to a non-explanation, $p<.001$, binomial test. Of the children who responded at least once by re-asking their original question, 31 out of 33 did so more often when they received a non-explanation as opposed to an explanation, $p<.001$, binomial test. Finally, 13 out of the 16 children who provided their own explanation at least once used this response more often following non-explanations than explanations, $p<.05$, binomial test.

\section{Children's Use of Questions versus Statements to Request Explanations}

As in Study 2, I confirmed that children's requestive statements functioned similarly to their questions regarding the surprising elements of the test items. This was especially important here because, relative to Study 2, children’s questions were less 
frequent and their requestive statements were more frequent. To parallel the analyses in Study 2, I looked at children’s reactions to explanations (collapsed across the level-1, -2, and -3 explanations within this study) versus their reactions to non-explanatory answers following these two types of initial responses.

As in Study 2, the pattern of children's reactions to explanations differed as predicted in comparison to their reactions to non-explanations (within the four key categories) both for questions and for requestive statements considered separately. When children asked a question initially and when they used a statement initially, they were more likely to agree/nod their heads, and to ask a follow-up question when they received an explanation than when they received a non-explanation (all $p<.05$ ). When children received a non-explanation in response to their question or requestive statement, they were more likely to re-ask their question, in contrast to when they received an explanation (both $p s<.001$ ). The only difference between instances when children asked a question initially and when they used a statement to acknowledge the unusual aspect of the stimulus was in the "provides own explanation" category, which showed a significant difference only for the instances when children used requestive statements $(p<.01)$. However, in the cases where children asked a question initially, providing their own explanations did go in the predicted direction of more frequently following nonexplanations than explanations.

Did Children Respond Differently to Explanations that Vary in their Amount of Detail?

I calculated proportions for each child by dividing the frequency of each type of child reaction following level-1 explanations by the number of level-1 explanations that the child received, and the same was done for level-2 explanations, level-3 explanations, 
and non-explanations. The data are presented in Table 5. An overall ANOVA indicated a significant difference in the patterns of child responses following these four types of adult responses, $F(24,1608)=7.43$, $\mathrm{p}<.001$.

Bonferroni post-hoc comparisons confirmed my hypothesis that the level-2 explanations would be the most satisfying. Children were significantly more likely to agree with level-2 explanations $(p<.05)$ and with level-3 explanations $(p<.05)$ compared to level-1 explanations. In addition, children were significantly more likely to agree with level-2 explanations compared to non-explanations, $p<.05$.

In line with the results from Study 1 and Study 2, children were significantly more likely to ask a follow-up question in response to level-1 explanations $(p<.001)$, level-2 explanations $(p<.01)$, and level-3 explanations $(p<.01)$, compared to nonexplanations. In contrast, children were significantly more likely to re-ask their original question following a non-explanation than following a level-1 explanation $(p<.001)$, a level-2 explanation $(p<.001)$, or a level-3 explanation $(p<.001)$. Finally, when providing their own explanations, children were significantly more likely to do this in response to a non-explanation than in response to a level-2 explanation $(p<.01)$ or a level-3 explanation $(p<.01)$.

Results for the other coding categories are reported in the bottom portion of Table 5. When children responded by smiling or laughing it was significantly more likely to be in response to a level-2 explanation or a level-3 explanation than in response to a level-1 explanation or a non-explanation (all $p<.05$ ). Matching results from Study 2, children were significantly more likely to disagree with non-explanations, than with level-1 explanations $(p<.05)$, level-2 explanations $(p<.01)$, or level-3 explanations $(p<.01)$. 
Are there Developmental Differences in Children's Patterns of Reactions?

In the prior analyses, there were no significant main effects or interactions involving age. But to confirm that results hold for the younger children (the 4-year-olds), separate analyses for this age group confirmed that they demonstrated the same pattern of reactions following the four different types of adult responses. Specifically, just as in the entire data, the 4-year-old children were more likely to agree with level-2 explanations compared to level-1 explanations, $p<.05$. These younger children were also significantly more likely to ask a follow-up question in response to level-1 explanations $(p<.05)$, level-2 explanations $(p<.05)$, and level-3 explanations $(p<.05)$, compared to non-explanations. These 4-year-olds were also significantly more likely to re-ask their original question following a non-explanation than following a level-1 explanation $(p<$ $.01)$, a level-2 explanation $(p<.01)$, or a level-3 explanation $(p<.01)$.

\section{Children's Recall of the Different Explanations and Non-Explanatory Answers}

Table 6 presents the percentage of the time children recalled the explanatory segments and non-explanations. The table is organized with the different types or levels of explanation in the rows and the segments that make up each level of explanation in the first three columns.

To analyze these data, first I compared whether the child participants recalled explanatory information better than non-explanatory information. As in Study 3, I compared participants' recall of the low detail explanations (containing only the E1 segment), medium detail explanations (averaging across the E1 and E2 segments, where participants could remember the E1 segment, the E2 segment or both segments), and high detail explanations (averaging across the E1, E2, and E3 segments, where the participant 
could remember the E1, E2 or E3 segment or any combination thereof) with their recall of the non-explanatory answers. In Table 6 this corresponds to a comparison between the fourth and fifth columns. All three of these paired $t$-tests were significant, with lowdetail explanations, $t(68)=9.46, p<.001$, medium-detail explanations, $t(68)=6.49, p<$ .001 , and high-detail explanations, $t(68)=4.74, p<.001$, being recalled more accurately than non-explanations.

Next, I conducted a series of planned comparisons to examine participants’ recall of the different explanatory segments within the explanations. As predicted, in the level2 and level-3 explanations, the recall of E2 segments was better than any other detail provided. Participants' recall of E2 segments was significantly better than their recall of E1 segments within both level-2 explanations, $t(48)=-7.79, p<.001$, and level-3 explanations, $t(48)=-5.61, p<.001$ (see the second and third rows of Table 6). Within level-3 explanations, participants’ recall of E2 segments was also significantly better than their recall of E3 segments, $t(48)=3.66, p<.01$. Importantly, these results show that children's tendency to recall the E2 segments so well in the level-2 explanations is not just because the E2 segment was the last part they heard. Even when the E2 segments are in the middle of the level-3 explanations, they are still the most frequently recalled.

Showing patterns similar to the adults, child participants recalled E1 segments best (67.8\% of the time) when these were the only information provided (in level-1 explanations). In comparison, as shown in the first column of Table 6, the recall of these segments significantly dropped to $29 \%$ when included in level-2 explanations, $t(68)=$ 7.68, $p<.001$, and to $27.1 \%$ when included in level-3 explanations, $t(68)=7.30, p<$ .001 (comparing recall within level-1 explanations to within level-3 explanations). 
When comparing participants' recall of explanatory segments with their recall of the non-explanations, my predictions were generally confirmed with the children. Children remembered the E1 segments of low-detail (level-1) explanations, $t(68)=9.46$, $p<.001$, the E2 segments from medium-detail (level-2) explanations, $t(68)=8.80, p<$ .001 , the E2 segments from high-detail (level-3) explanations, $t(68)=6.71, p<.001$, and the E3 segments of the high detail (level 3) explanations, $t(68)=2.63, p<.05$, all significantly better than the non-explanatory answers.

\section{Altering the Non-Explanations to be Explanatory}

I was interested to see whether child participants would alter the non-explanatory answers they were given to make them more explanatory. On $40.3 \%$ of trials children misremembered the non-explanation as if it were an explanation (by adding "because" $7.2 \%$ of the time and/or by coming up with an actual explanatory account $33.1 \%$ of the time). These "explanatory intrusions" illustrate the constructive nature of their recall: children seemed to expect to receive an explanation, and when they did not, they misrecalled the experimenter's response as if it were explanatory.

\section{Discussion}

When considering explanations versus non-explanations, the results from this study confirm the results from Study 2. Even the short, less-detailed level-1 explanations were recognized by children to be explanations. In comparison to non-explanations, these level-1 explanations were better remembered and inspired significantly more follow-up questions, and children reacted significantly less often by re-asking their original question. Note that these results also provide strong evidence against the hypothesis that children merely prefer longer answers to shorter ones, because the level-1 
explanations are actually shorter on average ( $M=4.25$ words) than the non-explanations ( $M=6.25$ words). Level-2 and level-3 explanations also demonstrate these same patterns in comparison to non-explanations.

When comparing between the different levels of explanation, results from this study suggest that children, like adults, find the medium level of detail (level-2) explanations to be the most satisfying. These level-2 explanations, in particular, receive high levels of agreement and smiling/laughing when compared with level-1 explanations. When extra detail beyond this level was added in the level-3 explanations, this did not change children's pattern of reactions, providing additional support for the idea that children are reacting to the content, rather than the length of the explanation provided.

In the recall task, children also distinguished between the explanatory and nonexplanatory information provided by the adult researcher. Children's recall of the nonexplanatory information was significantly less frequent than their recall of any of the explanations. This was a result I did not see in Study 3 because adults' recall of nonexplanations was very high and much more frequent than children's recall of this content. Aside from developmental differences in working memory, these differences can also be attributed to the differences between the two tasks. Adults saw each answer three times while completing the ratings portion of the study, whereas children heard the answers only once in a conversational context. In addition, adults may have been more willing to write down the non-explanation as an answer to a causal why-question than they would have been to state a non-explanation in response to the same why-question voiced aloud (as the children experienced). 
The instances when children inaccurately recalled the non-explanations as explanatory lend additional support to the idea that children are specifically motivated to seek explanations. These “explanatory intrusions” provided an interesting example of constructive childhood memory. Children apparently expected to receive an explanation, and when they did not, they frequently misremembered the adult's response as if it were explanatory. It is important to note that there were also instances of children, when prompted to recall what the researcher had said about why the puzzle piece did not fit or the bed was outside, etc., responding by accurately saying that the researcher had not told them this information.

With regard to their recall of the individual explanatory segments, children generally showed the expected patterns (also generally shown by adults), with the detail provided in E2 segments in the level-2 and level-3 explanations being the most memorable. That this information was still the most frequently recalled even when it was in the middle of the level-3 explanations (where there was no primacy or recency effects), suggests that there is something special about this segment. Is it because the E2 segment is an optimal length, with the E3 details being forgotten because they are excessive and unnecessary? Or perhaps is there something special about the content of these segments? I will discuss this point in more detail in the general discussion. 


\section{CHAPTER VII}

\section{General Discussion}

Across the studies presented in this paper, I have provided evidence to support the hypothesis that preschool-aged children actively seek explanatory information within conversations with adults. By examining children's reactions to an adult's provision of explanations versus non-explanatory answers in response to their inquiries, in both naturalistic (Study 1) and experimental (Studies 2 and 4) contexts, children demonstrate evidence of satisfaction when they receive explanations, and continued inquiry when they receive non-explanatory answers. In addition, results from Studies 3 and 4 suggest that both adults and children prefer and have a better memory for explanations that are neither under- nor overly-detailed, but instead contain a mid-level of detail.

These findings are important for several reasons. First, as was mentioned in the discussion of the first two studies, I have identified a methodology for assessing children's explanatory preferences within a conversational context representative of experiences they have in their everyday lives. Children have numerous opportunities to engage adults in conversation, and I have demonstrated how these conversations in fact provide a means for children to actively acquire explanatory information. In addition, this research has demonstrated that examining conversational exchanges and pushing beyond questions and answers to specifically look at the third step in conversation (children's reactions) provides fruitful insight into not only the intention behind the initial 
inquiry, but also how children evaluate the content of the answer they receive. This methodology has promising potential for use in future research.

Additionally, the finding that both adults and children have similar preferences for explanations containing a mid-level of detail not only challenges the notion that more detail is always better in explanations, but also challenges the idea that adults and children are satisfied with minimally detailed or "shallow" explanations. It appears that there is an optimal level of "explanatory depth" for explanations, demonstrated across Studies 3 and 4 using multiple means of assessment including adults' ratings of satisfaction, children's conversational reactions and both adults' and children's recall. Both adults and preschool-aged children followed similar patterns in their recall, with the E2 segments being the most frequently recalled even when this information was in the middle of the level-3 explanations, counteracting both primacy and recency effects.

However, within this research, it is still an open question as to what it is exactly about the level-2 explanations, and specifically the E2 segments, that makes them the most satisfying. Is it that they are merely an optimal length (neither too short nor too long)? The results from the studies presented here argue against length as the primary factor in participants' satisfaction. The non-explanations from Studies 3 and 4 are not more satisfying, despite being longer than the level-1 explanations. Additionally, children's patterns of responses are the same following level-2 explanations and longer level-3 explanations. Finally, looking at the ratings for individual items, there was no systematic trend between adults' satisfaction ratings and the relative length of the explanations. Items with longer level-1 explanations (with word lengths closer to the 
range for level-2 explanations) were not systematically more satisfying than the shorter level-1 explanations.

Another possible hypothesis, which is the one favored here, is that there something special about the nature of the information provided in the E2 segments. The challenge is how best to characterize the content of these segments and explain what intuitively seems to make them qualitatively different from the E1 and E3 segments. The E1 segments, while they do function as explanations when presented alone in level-1 explanations, only provide details that situate the explanation within a domain. For example, "I wanted it that way” and "She didn’t mean to" signal psychological causes, whereas “It’s stuck” and “Regular doors are too big for Julia” signal physical causes. However, in order to best understand the situation, these E1 segments seem to prompt a further question of why "it's stuck" or why "I wanted it that way." The E2 segments answer these questions, by providing information about the underlying "purpose,” “rationale,” or “cause” (I put these terms in quotes because it is difficult to find an overarching term to best characterize the nature of this information). In other words, the E2 segments seem to really get to the heart of the matter, in a way that is both appropriately specific and yet also still generalizable to other similar situations, past experiences, or prior knowledge.

Anecdotal evidence from Study 4 supports this idea that the details provided in the E2 segments fit especially well within children's prior knowledge. One example of this is that for the storybook item with the boy who puts orange juice on his cereal, instead of recalling "milk makes him sick" on several occasions children said instead 
"he’s allergic" suggesting that they had fit the information provided by the adult into an explanatory knowledge they already possessed about food allergies.

The question remains then of how best to describe the nature of the E3 segments. I believe the notion of generalizability may be related to the nature of the E3 segments. For most of the items, it seems as if the additional details provided in the E3 segments are ones that could be inferred easily (perhaps from one's own past experiences or knowledge) once the E2 information is known.

It is important to mention two other factors that also might be contributing to why the E2 segments were particularly satisfying and memorable. As mentioned previously, these studies did not control for the domain in which each explanatory segment was situated and instead used a variety of psychological, physical and biological explanatory segments across the different items. Additionally, there was also variation in what the building explanatory segments (the E2 and E3 segments) contributed to the explanations. In some cases, these segments created a "causal chain" in which the additional segment provided new explanatory information (as if answering an additional "why” question); whereas in other cases, these segments only added detail to the previous segment, without any new explanatory information. For example, the E3 segment for the girl who pours ketchup on her ice cream ("because the ketchup bottle and the chocolate bottle look the same”) provides new explanatory information regarding why she thought there was ketchup in the bottle, whereas the E3 segment for the girl who goes to bed with her clothes on ("into her pajamas") merely provides additional detail. Exploring how these factors contribute to adults’ and children's satisfaction and memory of different explanations is an important task for future research. 
There are other limitations to this research that should be acknowledged. First, while the results did show significant differences in the way children reacted to different types of adult answers, it should be noted that, particularly in Study 4, instances when the children did not provide a reaction were relatively frequent. The increased frequency of these "no response” instances in Study 4 compared to Study 2 is likely due to two factors: the children's familiarity with the researcher and the pace at which the researcher moved through the items. Study 2 was primarily conducted in the university preschool setting where the researcher had spent at least two hours (across multiple visits) building rapport with the children prior to the study. In contrast, Study 4 was primarily conducted in preschools were the researcher visited for a single day and had only minimal contact with the children prior to their participation in the study. It is likely that children feel more comfortable and react more frequently in conversations with adults they are more familiar with compared to those they have only recently met. In addition, in Study 4, because of the added time needed for the distraction and recall tasks, it was necessary that the researcher move through the items at a faster pace than had previously been used in Study 2. Perhaps if given more time to react, children in Study 4 may have provided more responses.

Another potential limitation of this research concerns an additional possible source of information children might use to identify and distinguish explanations from non-explanations. The researchers in Studies 2 and 4 aimed to use the same amount of enthusiasm across both explanatory and non-explanatory answers. However, it is possible that in conversational contexts, adults' responses may contain intonational cues that (either intentionally or unintentionally) signal a difference between explanations and 
non-explanatory information. The videotaped data from Study 2 and 4 in this project could be used to check for differences in intonation, but an even more interesting possibility would be to examine the intonational cues present in naturalistic adult-child explanatory conversation. In the same way that child-directed speech (or "motherese”) may aid children’s language development, perhaps there is an “explanationese” that signals the importance of explanatory information.

A final limitation of this research concerns the demographics of the preschool children included in the samples for Study 2 and Study 4. These children were recruited from predominantly Caucasian, mid to high-income communities, where the cultural context is one that supports and encourages children to directly inquire for information from the adults around them. The results from these studies may not extend to other cultural contexts where the expectations and norms for interacting with adults may be different for children. Rather than initiating causal inquiry through conversation, children may have different strategies for obtaining explanatory knowledge in these contexts.

Several questions remain for future research. First, what is the developmental course of these patterns? I have explored preschool-aged children's questions and their reactions to the answers they receive, but it would be interesting to know when these patterns first emerge. The earliest data in these studies is from the transcripts of 2-yearolds in Study 1 as they are voicing their first causal questions. Do children request explanatory information prior to their ability to verbalize causal questions? In Chouinard's (2007) study, she provides some insight into this question. Using a dairy methodology, over the course of a week parents of children as young as 1 year old 
recorded instances where they appeared to be requesting information using gestures, expressions and vocalizations. Chouinard (2007) reports that while requests for explanatory information at this age were rare (only $3 \%$ of the time with the rest of the requests being for fact-based information), they did exist. It would be interesting to know if, at this young age, children would persist in requesting explanatory information if they did not first receive it.

It is also an open question as to how children's reactions and explanatory preferences might change after the age of 5. In Study 1, across the ages of 2 to 4 years old, the frequency of adults' provision of explanations decreased, while at the same time, the frequency of children providing their own explanations increased. I believe that this might be evidence of a developmental change in the nature of these adult-child explanatory conversations. As the children get older, they are better able to verbalize and figure out on their own possible explanations for the questionable phenomena around them. With children’s increasing capabilities, adults' role may shift from providing immediate explanations in response to children's inquiries to instead providing supporting details that encourage children to come up with explanatory possibilities themselves.

With regard to children's preferences for a particular level of explanatory detail, results from Studies 3 and 4 suggest that there may be little developmental change between the ages tested here and adulthood. It was especially interesting to see that adults and 4- and 5-year-olds showed such similar patterns across the different levels of explanatory detail (both in measures of satisfaction and in recall). Preferences for the optimal level of detail for an explanation appear to be established early, but when and 
how these preferences emerge is a fascinating question for future research. One avenue for exploration with regard to this question might be examining the level of detail present in parents' explanations. This approach would be similar one taken by Kelemen, Callanan, Casler and Perez-Granados (2005) who coded parents’ explanatory modes in an effort to investigate one possible origin (parental modeling) of children's tendency to produce a teleological explanations. However, parents' explanations did not demonstrate the same teleological bias as children's and were instead primarily causal and only rarely teleological. With regard to the amount of explanatory detail, how much parental modeling affects the explanations children prefer and produce remains an open question. There is also the question of whether the patterns in child reactions following explanations and non-explanations might change based on the child's conversational partner. Does the child's sense of their conversational speaker's expertise play a role in how they respond to the information they receive? Are adults, such as parents, teachers, and researchers, seen as more knowledgeable (and therefore more credible) by the child compared to fellow peers, students, or siblings? And if so, does this affect how children treat explanatory responses, and which do they find most satisfying? I would expect that the expertise of the conversational partner would play the greatest role in situations where the explanation provided conflicts with the child's intuitions or past knowledge. In these cases, children would probably be more likely to agree with the explanations of individuals they see as expert and more likely to disagree or reject the explanations of those they see as less knowledgeable (or direct their question elsewhere). It would be interesting, in future research, to design a task with multiple conversational partners 
whose explanations vary in their accuracy or amount of detail and then see which person the child chooses to address his/her questions toward.

Finally, there is the issue of whether there are domain differences in the sorts of explanations children find most satisfying. In Study 3 and 4, the different levels of explanations often combined explanatory information from more than one domain. For instance, "It was a mistake because she thought it was chocolate in the bottle because the ketchup and the chocolate bottle look the same” combines information across psychological and physical domains, and the explanation, “He wanted orange juice because milk makes him sick” combines across both psychological and biological domains. Are these sorts of explanations that span across several domains potentially more satisfying that those that provide detail within a single domain? Perhaps providing information from multiple domains would allow children to make explanatory connections across domains, or if children have a specific domain in mind when they make an inquiry, perhaps multiple domain answers might just have a better chance of covering that target domain. Would children react with indications of dissatisfaction or have poor recall for explanations that are not within the domain they had in mind? These are open questions for future research that could be explored using methodology similar to Study 4, using explanations that span across multiple domains versus explanations that provide detail within a single domain. The challenge for a study like this would be determining domain for which the child is requesting information.

Children’s building of explanatory knowledge is without doubt a complicated and multi-faceted process, but by examining the patterns in adult-child conversational 
exchanges, this research has provided a glimpse into how this one part of this process unfolds within children's everyday lives. 
Table 1. Study 1: Percentage of Child Reactions Following Adult Explanations versus Non-Explanatory Responses $(N=6)$

\begin{tabular}{lccc}
\hline & \multicolumn{2}{c}{ Adult Response } & \\
\hline Child Reactions & Explanation & $\begin{array}{c}\text { Non-Explanatory } \\
\text { Response }\end{array}$ & $\begin{array}{c}\text { Signif. } \\
\text { (two tailed) }\end{array}$ \\
\hline Agrees or says “oh” & $11.6 \%$ & $6.3 \%$ & $* *$ \\
Asks a follow-up question & $18.5 \%$ & $4.6 \%$ & $* *$ \\
Re-asks original question & $9.4 \%$ & $24.0 \%$ & $* *$ \\
Provides own explanation & $1.0 \%$ & $10.7 \%$ & $*$ \\
\hline Disagrees with adult response & $3.4 \%$ & $1.6 \%$ & $* .9 \%$ \\
Provides additional on-topic supporting details & $15.3 \%$ & $17.3 \%$ & $* .5 \%$ \\
Changes topic & $20.7 \%$ & $15.5 \%$ \\
No response & $20.5 \%$ & & $* *$ \\
\hline
\end{tabular}

$* p<.01, * * p<.001$

A conservative $p<.01$ level of significance is applied to these results. 
Table 2. Study 2: Percentage of Child Reactions Following Adult Explanations versus Non-Explanatory Responses $(N=42)$

\begin{tabular}{|c|c|c|c|}
\hline \multirow[b]{2}{*}{ Child Reactions } & \multicolumn{2}{|c|}{ Adult Response } & \multirow[b]{2}{*}{ Signif. } \\
\hline & Explanation & $\begin{array}{c}\text { Non-Explanatory } \\
\text { Response }\end{array}$ & \\
\hline Agrees, nods head, or says “oh” & $29.5 \%$ & $12.6 \%$ & $* *$ \\
\hline Asks a follow-up question & $21.4 \%$ & $6.6 \%$ & $* *$ \\
\hline Re-asks original question & $1.2 \%$ & $21.4 \%$ & $* *$ \\
\hline Provides own explanation & $0.7 \%$ & $4.0 \%$ & $*$ \\
\hline Smiles or laughs & $7.0 \%$ & $0.9 \%$ & $* *$ \\
\hline Disagrees with adult response & $0.7 \%$ & $5.8 \%$ & $* *$ \\
\hline Provides additional on-topic supporting details & $12.4 \%$ & $18.6 \%$ & n.s. \\
\hline Changes topic or asks for next item & $7.3 \%$ & $8.1 \%$ & n.s. \\
\hline No response & $19.8 \%$ & $22.0 \%$ & n.s. \\
\hline
\end{tabular}

$* p<.05, * * p<.01$ 
Table 3. Study 3: Adult Average Ratings of Each Type of Answer $(N=43)$

\begin{tabular}{|c|c|c|c|c|}
\hline & $\begin{array}{l}\text { Low Detail } \\
\text { Explanations } \\
\text { ( level-1 ) }\end{array}$ & $\begin{array}{l}\text { Med. Detail } \\
\text { Explanations } \\
\text { ( level-2 ) }\end{array}$ & $\begin{array}{l}\text { High Detail } \\
\text { Explanations } \\
\text { ( level-3 ) }\end{array}$ & $\begin{array}{l}\text { Non- } \\
\text { Explanations } \\
(\mathrm{NE})\end{array}$ \\
\hline $\begin{array}{l}\text { Does this answer provide an } \\
\text { explanation to the question? } \\
\text { (percentage of the time the } \\
\text { participants answered "yes") }\end{array}$ & $84.7 \%^{a}$ & $98.8 \%^{b}$ & $99.4 \%^{b}$ & $7.8 \%{ }^{c}$ \\
\hline $\begin{array}{l}\text { How satisfying is this answer? } \\
\text { (rated on a 1-6 scale) }\end{array}$ & $3.53^{a}$ & $4.25^{b}$ & $4.23^{b}$ & $1.76^{\mathrm{c}}$ \\
\hline How long is this answer? & $1.74^{\mathrm{a}}$ & $3.93^{b}$ & $5.22^{c}$ & $2.35^{d}$ \\
\hline $\begin{array}{l}\text { (rated on a 1-6 scale; actual length } \\
\text { is in parentheses) }\end{array}$ & (4.25 words) & (11.25 words) & (20.08 words) & (6.25 words) \\
\hline
\end{tabular}

Significant differences are indicated by contrasting superscripts. 
Table 4. Study 3: Percentage of the Time Adults Recalled Each Answer Segment $(N=49$ for comparisons between explanation segments, $N=33$ for comparisons between explanation segments and the non-explanation)

\begin{tabular}{|c|c|c|c|c|c|}
\hline & $\begin{array}{c}\text { ( E1 ) } \\
\text { Segment }^{\text {a }}\end{array}$ & $\begin{array}{c}(\mathrm{E} 2)^{\text {Segment }} \\
{ }^{b}\end{array}$ & $\begin{array}{c}\text { ( E3 ) } \\
\text { Segment }\end{array}$ & $\begin{array}{l}\text { Average } \\
\text { across the } \\
\text { segments } \\
(N=33)\end{array}$ & $\begin{array}{c}\text { ( NE ) } \\
\text { Segment }\end{array}$ \\
\hline $\begin{array}{l}\text { Low Detail } \\
\text { Explanations } \\
\text { ( level-1 ) }\end{array}$ & 98.3 & - & - & 97.5 & - \\
\hline $\begin{array}{c}\text { Medium } \\
\text { Detail } \\
\text { Explanations }{ }^{\mathrm{c}} \\
\text { ( level-2 ) }^{\text {level }}\end{array}$ & 77.6 & 96.9 & - & 90.7 & - \\
\hline $\begin{array}{l}\text { High Detail } \\
\text { Explanations } \\
{ }^{\mathrm{d}} \\
\quad \text { (level-3 ) }\end{array}$ & $68.4 *$ & 91.7 & 86.4 & 85.6 & - \\
\hline $\begin{array}{l}\text { Non- } \\
\text { Explanations } \\
\text { ( NE ) }\end{array}$ & - & - & - & - & 87.4 \\
\hline
\end{tabular}

Significant differences between recall of the explanatory segments and recall of the nonexplanation are indicated by stars: $* p<.05$.

Pair-wise comparisons:

a. E1 segment: recall in level-1 is significantly different from recall in level-2, $p<.001$; recall in level-1 is significantly different from recall in level-3, $p<.001$

b. E2 segment: recall in level-2 is significantly different from recall in level-3, $p<.05$

c. Level-2 explanation: recall of E1 is significantly different from recall of E2, $p<.001$

d. Level-3 explanation: recall of E1 is significantly different from recall of E2, $p<.001$; recall of E1 is significantly different from recall of E3, $p<.01$ 
Table 5. Study 4: Percentage of Child Reactions Following Adult Explanations versus Non-Explanatory Responses $(N=69)$

\begin{tabular}{|c|c|c|c|c|}
\hline \multirow[b]{2}{*}{ Child Reaction } & \multicolumn{4}{|c|}{ Adult Response } \\
\hline & $\begin{array}{l}\text { Low Detail } \\
\text { Explanation } \\
\text { ( level-1 ) }\end{array}$ & $\begin{array}{l}\text { Medium Detail } \\
\text { Explanation } \\
\text { ( level-2 ) }\end{array}$ & $\begin{array}{l}\text { High Detail } \\
\text { Explanation } \\
\text { ( level-3 ) }\end{array}$ & $\begin{array}{l}\text { Non-Explanatory } \\
\text { Response } \\
\text { ( NE ) }\end{array}$ \\
\hline Agrees, nods head, or says “oh” & $10.9^{\mathrm{a}}$ & $19.9^{\mathrm{b}, *}$ & $18.2^{b}$ & 10.2 \\
\hline Asks a follow-up question & $16.9^{*}$ & $11.6^{*}$ & $12.3^{*}$ & 2.9 \\
\hline Re-asks original question & $1.9^{*}$ & $1.1^{*}$ & $0.3^{*}$ & 18.0 \\
\hline Provides own explanation & 1.8 & $0^{*}$ & $0.7^{*}$ & 4.9 \\
\hline Smiles or laughs & $4.1^{\mathrm{a}}$ & $11.8^{\mathrm{b}, *}$ & $16.2^{\mathrm{b}, *}$ & 2.2 \\
\hline Disagrees with adult response & $0.4^{*}$ & $0.3^{*}$ & $0^{*}$ & 4.0 \\
\hline $\begin{array}{l}\text { Provides additional on-topic supporting } \\
\text { details }\end{array}$ & 17.3 & 11.2 & 10.4 & 14.4 \\
\hline Changes topic or asks for next item & 6.2 & 7.0 & 7.3 & 4.5 \\
\hline No response & 40.6 & 37.0 & 34.4 & 39.0 \\
\hline
\end{tabular}

Significant differences between the three different explanation types are indicated by contrasting superscripts, $p<.05$.

Significant differences between an explanation type and the non-explanatory responses are indicated by stars, $p<.05$. 
Table 6. Study 4: Percentage of the Time Children Recalled Each Answer Segment $(N=69)$

\begin{tabular}{|c|c|c|c|c|c|}
\hline & $\begin{array}{c}(\mathrm{E} 1) \\
\text { Segment }\end{array}$ & $\begin{array}{c}(\mathrm{E} 2)^{2} \\
\text { Segment }^{\mathrm{b}}\end{array}$ & $\begin{array}{c}\text { ( E3 ) } \\
\text { Segment }\end{array}$ & $\begin{array}{l}\text { Average } \\
\text { across } \\
\text { segments }\end{array}$ & $\begin{array}{c}\text { ( NE ) } \\
\text { Segment }\end{array}$ \\
\hline $\begin{array}{l}\text { Low Detail } \\
\text { Explanations } \\
\text { ( level-1 ) }\end{array}$ & $67.8 *$ & - & - & $67.8 *$ & - \\
\hline $\begin{array}{l}\text { Medium Detail } \\
\text { Explanations }{ }^{\mathrm{c}} \\
\quad(\text { level-2 ) }\end{array}$ & 29.0 & $71.7 *$ & - & $50.4 *$ & - \\
\hline $\begin{array}{l}\text { High Detail } \\
\text { Explanations } \\
\quad \text { ( level-3 ) }\end{array}$ & 27.1 & $57.7 *$ & $32.4 *$ & $39.1 *$ & - \\
\hline $\begin{array}{l}\text { Non- } \\
\text { Explanations } \\
\text { ( NE ) }\end{array}$ & - & - & - & - & 18.8 \\
\hline
\end{tabular}

Significant differences between recall of the explanatory segments and recall of the nonexplanation are indicated by stars: ${ }^{*} p<.05$

Pair-wise comparisons:

a. E1 segment: recall in level-1 is significantly different from recall in level-2, $p<.001$; recall in level-1 is significantly different from recall in level-3, $p<.001$

b. E2 segment: recall in level-2 is significantly different from recall in level-3, $p<.01$

c. Level-2 explanation: recall of E1 is significantly different from recall of E2, $p<.001$

d. Level-3 explanation: recall of E1 is significantly different from recall of E2, $p<.001$; recall of E2 is significantly different from recall of E3, $p<.01$ 


\section{Appendix A}

\section{Coding Categories Used in Study 1}

\section{Form of Child's Question}

1. fully-formed, including an articulated topic ("Why is the sky blue?”)

2. single-word or not including topic ("Why?” "How come?” "Why not?”)

Examples of questions that were not included (close imposters of causal questions):

“How’s that?” "How was it big?” "How would you like to go find bones from that guy?” "How does that sound?” "I know why dey so tiny.” "Did you show Ursula how to do it?” “See how dark it is?” “How ya like that?”

\section{$\underline{\text { Adult Response Categories }}$}

a) Explanation

\section{Examples:}

CHILD: Why you making tacos? ADULT: I thought you'd like them.

CHILD: Why you put some water in there, Mom? ADULT: To help mix all of the ingredients together.

CHILD: Why I have red hands? ADULT: Because pomegranate juice is red, right?

CHILD: Why the mailman got this to me? ADULT: Because he likes you.

CHILD: Why dose lobsters? ADULT: Because that's what they were born to be.

b) Non-Explanatory Answer (includes: providing new or focusing information, redefining or correcting assumptions underlying the child's question, confirming/agreeing with the child's question, asking a clarification question, redirecting 
the question to someone else, saying “I don’t know,” “Because” or "Because I said so," or not responding.

Examples:

CHILD: Why some are white? ADULT: That's not white; that's brown, isn't it? CHILD: Why some are brown, some are yellow? ADULT: You were right at first. CHILD: “How can snakes hear if they don't have ears?” ADULT: “I don't think they can hear.”

CHILD: "How you erase the red off?” ADULT: "It's harder than the black to erase.”

CHILD: "Why clowns put some powder on the face?" ADULT: "Why do ya think?”

ADULT: “Don’t touch it now.” CHILD: “Why?” ADULT: “Because!”

CHILD: “Why?” ADULT: “Because that's one of those questions I just can't answer, honey.”

CHILD: “How do you make your voice go on?” ADULT: “I’ll show you in a minute.”

CHILD: "Why does he push this?” ADULT: "He’s just pushing it." CHILD: "Why did they send those toys back to America?” ADULT: "Which toys, honey?”

CHILD: “Why are all the cars stopped over there?” ADULT: "Do you really think they’ve stopped on the other side?” 


\section{$\underline{\text { Explanation Forms }}$}

1. Mechanism: Procedure-like explanations in which a step or series of steps were mentioned as a way of explaining how something works.

Example: CHILD: Why it can’t turn off? ADULT: Because the springs are all wound up.

2. Prior Causal Event: Explanations that provide a single event that occurred prior to and caused the asked-about event.

Example: CHILD: Why my tummy so big, Mom? ADULT: Because you ate a lot. 3. Consequence: Explanations that provide a purpose for, or an event or state that will occur later in time than, the asked-about event or state. Includes teleological explanations, which assume that objects, behaviors or events occur or exist for a purpose (Kelemen, 1999).

Example: CHILD: Why does Andy go to the barber? ADULT: To get his hair cut. 4. Current State of World, Non-Mechanism: Explanations that refer to the existence of an object/entity or the state/quality of a situation that is the cause of the asked-about phenomenon; does not mention a specific mechanism.

Example: CHILD: Why not keep a light on? ADULT: Because we have the sun.

5. Other

\section{$\underline{\text { Child Response Categories }}$}

a) Agrees with adult

Includes: agreeing with adult response, saying “yes/yeah” or “oh,” or repeating adult response 
b) Asks a Follow-Up Question

Includes: asking a question that is on the same general topic as the original question, but requests different information than was requested in the original question

Example: CHILD: Why they going deep-sea diving? ADULT: (no response)

CHILD: How are the people going down dere?

c) Re-asks Original Question

Includes: repeating or rephrasing the original question; requests the same information as the original question

Example: CHILD: How are the people going down dere? ADULT: (no response)

CHILD: How dey going to get there?

d) Provides his/her Own Explanation

Includes: offering an alternative explanation to the one the adult has provided or providing an explanation when the adult has not given one

Example: CHILD: How come the airplanes wanted to shoot the mean monster?

ADULT: They thought the monster would come to their city and eat it. CHILD:

No, the monster crashed the planes down like this.

Example: CHILD: Do you know why he's going to live next to the mine?

ADULT: How come? CHILD: Because he likes it next to the mine.

e) Disagrees with adult

f) Provides Additional On-Topic Supporting Details

Example: CHILD: Why did you give me the blue one? ADULT: (no response)

CHILD: I wanted the red one. 
g) Changes topic

h) No response

Includes: silence (no response) or making an unintelligible or incomplete response 
Appendix B

Explanations and Non-Explanatory Answers Given in Response to Child Inquiries in Study 2

\begin{tabular}{|c|c|c|c|}
\hline Stimuli: Objects & Question & Explanation & Non-Explanation \\
\hline 1. Animal puzzle & Why doesn’t this piece fit? & $\begin{array}{l}\text { I think the pieces from two } \\
\text { puzzles got mixed up. }\end{array}$ & $\begin{array}{l}\text { I think all the other pieces fit in } \\
\text { this puzzle. }\end{array}$ \\
\hline 2. Red crayons & Why are all of these red? & $\begin{array}{l}\text { I'll bet it's because the factory } \\
\text { messed up. }\end{array}$ & You're right, they are all red. \\
\hline 3. Hat with hole & $\begin{array}{l}\text { Why does this have a hole } \\
\text { in it? }\end{array}$ & It's to put a ponytail through. & $\begin{array}{l}\text { Hats don't usually have holes } \\
\text { in them. }\end{array}$ \\
\hline 4. Cell phone glued shut & Why doesn’t this open? & $\begin{array}{l}\text { Oh, I think it was broken and } \\
\text { somebody accidentally glued it } \\
\text { shut. }\end{array}$ & $\begin{array}{l}\text { It looks like it has some } \\
\text { buttons on the outside. }\end{array}$ \\
\hline
\end{tabular}

\section{Stimuli: Storybooks}

1. Ice cream and ketchup Why did she do that?

2. Clothes in bed

Why did she do that?

3. Cereal and orange juice Why did he do that?

\section{Explanation}

She thought it was chocolate syrup.

She was so tired that she fell asleep before putting her pajamas on.

He thought it was milk in the pitcher.

\section{Non-Explanation}

That looks like vanilla ice cream.

I like to sleep under lots of covers when I go to bed.

I like to put milk on my cereal. 


\begin{tabular}{|c|c|c|c|}
\hline $\begin{array}{l}\text { 4. Playing outside with } \\
\text { scarf }\end{array}$ & Why did he do that? & $\begin{array}{l}\text { He wanted to play a joke on } \\
\text { his friend. }\end{array}$ & $\begin{array}{l}\text { Yeah, he's wearing a scarf } \\
\text { when it's hot outside. }\end{array}$ \\
\hline
\end{tabular}

\section{Stimuli: Pictures}

1. Nest with turtle

2. Little door

3. Clown nose

4. Bed outside

Stimuli: Videos

1. Light switch with foot

2. Spin in hallway

3. Bucket as hat

4. Hat stomp

\section{Question}

Why is the turtle in that nest?

Why is that door so small?

Why is he wearing a red nose?

Why is Tommy's bed outside?

Question

Why did Brandy do that?

Why is Brandy doing that?

Why did you do that?

Why did you do that?

\section{Explanation}

You know, I think the turtle crawled in there by mistake.

You know, I'm pretty sure it's a fairy door.

He works as a clown and forgot to take it off.

Tommy's parents are painting his room.

Explanation

Brandy didn't want to touch the light switch with her sticky hands.

\section{I'm pretty sure Brandy's} practicing a dance move.

I'm pretending the blue bucket is a hat.

There was a bug in my hat.

\section{Non-Explanation}

You're right, there is a turtle in that bird's nest.

I think doors are usually much bigger than that.

People don't usually wear red noses like that.

I think that bed looks comfortable.

\section{Non-Explanation}

I like the color of the shirt that Brandy's is wearing.

I like how Brandy is spinning in the hallway.

I didn't put the hat on my head.

People don't usually jump on hats. 


\section{Appendix C}

Coding Categories Used For Child Responses in Study 2

a) Agrees, nods head or says “oh”

Example: ADULT: I think the pieces from two puzzles got mixed up.

CHILD: Me too.

b) Asks a follow-up question, including clarification questions

Example: ADULT: Brandy didn't want to touch the light switch with her sticky hands. CHILD: Why her hands were sticky?

Example: ADULT: I'm pretty sure that's a fairy door. CHILD: What's a fairy door?

Example: ADULT: Tommy’s parents are painting his room. CHILD: So they put it outside?

c) Re-asks original question Example: CHILD (original question): Why did he? ADULT: I like to put milk on my cereal. CHILD: Why did he pour orange juice in his cereal?

d) Provides own explanation

Example: ADULT: I'll bet it's because the factory messed up. CHILD: Well, maybe because someone took them out and put a lot of reds in there. Maybe a leprechaun did that.

e) Smiles or Laughs

f) Disagrees with adult response

Example: ADULT: I like to put milk on my cereal. CHILD: Not me. 
Example: ADULT: People don’t usually wear red noses like that. CHILD: Some do. Deers have red noses.

g) Provides additional on-topic supporting details

Example: ADULT: You know, I think the turtle crawled in there by mistake.

CHILD: I think that bird's trying to eat the turtle.

Example: ADULT: You're right, there is a turtle in that bird's nest. CHILD: I like turtles.

h) Changes the topic or asks for next item

Example: ADULT: I'm pretending the blue bucket is a hat. CHILD: You have a different shirt on.

Example: CHILD: Now let's see another story.

i) No response 


\section{Appendix D}

Answers Used in Study 3 and Study 4: Three Types of Explanations and the NonExplanations

E1: Explanation with low level of detail

E2: Explanation with medium level of detail

E3: Explanation with high level of detail

NE: Non-explanatory answer

\section{Box of crayons that are all one color}

E1: It was a mistake.

E2: It was a mistake in packaging at the crayon factory.

E3: It was a mistake in packaging at the crayon factory and the machine put all the same color crayons into one box.

NE: They are all the same color.

\section{Hat with a hole in it}

E1: The owner wanted it that way.

E2: The owner wanted it that way so her ponytail could fit through the hole.

E3: The owner wanted it that way so her ponytail could fit through the hole, so she cut a hole in it with her scissors.

NE: Hats don’t usually have holes in them.

\section{Phone that will not open}

E1: It's stuck.

E2: It's stuck because somebody spilled glue on it. 
E3: It's stuck because somebody spilled glue on it and the glue ran into the crack and pasted it together.

NE: It looks like a young girl's cell phone.

\section{Puzzle with piece that does not fit*}

E1: This piece is too tall.

E2: This piece is too tall because two puzzles got mixed up.

E3: This piece is too tall because two puzzles got mixed up and this piece goes to a different puzzle.

NE: All the other pieces fit in this puzzle.

* Children always received always the non-explanation for this item

\section{Girl who puts ketchup on her ice cream}

E1: It was a mistake.

E2: It was a mistake because she thought it was chocolate in the bottle.

E3: It was a mistake because she thought it was chocolate in the bottle because the ketchup bottle and the chocolate bottle look the same.

NE: That looks like vanilla ice cream.

\section{Girl who goes to sleep with her clothes and shoes on}

E1: She didn’t mean to.

E2: She didn't mean to, but she was really tired so she fell asleep without changing.

E3: She didn’t mean to, but she was really tired so she fell asleep without changing into her pajamas.

NE: Some people sleep under lots of covers when they go to bed.

\section{Boy who puts orange juice on his cereal}


E1: He wanted orange juice.

E2: He wanted orange juice because milk makes him sick.

E3: He wanted orange juice because milk makes him sick, so he has to have his cereal with juice instead.

NE: Most people put milk on their cereal.

\section{Boy who wears hat, scarf and gloves in hot weather *}

E1: He wanted to.

E2: He wanted to play a joke on his friend.

E3: He wanted to play a joke on his friend so he put on all his winter clothes even though it was hot outside.

NE: He’s wearing all his winter clothes.

* Children always received always the non-explanation for this item

\section{Turtle in a bird's nest}

E1: He crawled in there.

E2: He crawled in there because he was looking for something to eat.

E3: He crawled in there because he was looking for something to eat and he couldn't see what was in the nest.

$\mathrm{NE}$ : He is in a bird's nest.

\section{Miniature door}

E1: Regular doors are too big for Julia.

E2: Regular doors are too big for Julia because she’s a mouse.

E3: Regular doors are too big for Julia because she’s a mouse and she can’t reach the doorknob on a big door. 
NE: Doors are usually much bigger than that.

\section{Man wearing a red nose}

E1: He works as a clown.

E2: He works as a clown and he forgot to take it off.

E3: He works as a clown and he forgot to take it off because he didn't look in the mirror.

NE: People don't usually wear red noses like that.

\section{Bed outside the house *}

E1: Tommy’s parents moved it outside.

E2: Tommy's parents moved it outside because they are painting his room.

E3: Tommy’s parents moved it outside because they are painting his room and they didn’t want to get paint on it.

NE: That bed is very comfortable.

* Children always received always the non-explanation for this item

\section{Girl turns off light switch with her foot}

E1: She didn't want to use her hands.

E2: She didn’t want to use her hands because they were sticky.

E3: She didn’t want to use her hands because they were sticky because some jelly squished out of her sandwich.

NE: She’s wearing a pretty blue shirt.

\section{Girl spins while walking down a hallway}

E1: She’s practicing.

E2: She’s practicing so she will be ready for her dance class. 
E3: She's practicing so she will be ready for her dance class because when she practices, she gets better.

NE: She looks like she's going fast.

\section{Girl puts a bucket on her head instead of a hat}

E1: She's pretending.

E2: She's pretending the blue bucket was a fairy crown.

E3: She's pretending the blue bucket was a fairy crown so she could be a beautiful fairy princess.

NE: She didn't put the hat on her head.

\section{Girl takes off her hat and jumps on it *}

E1: She's trying to squish it.

E2: She's trying to squish it because she felt a bug in it.

E3: She's trying to squish it because she felt a bug in it and she doesn't like bugs.

NE: People don’t usually jump on hats.

* Children always received always the non-explanation for this item 
Appendix E: Coding Scheme for Study 3 and Study 4 Recalled Answers

\begin{tabular}{|c|c|c|c|}
\hline 1. crayons & $\begin{array}{l}\text { It was a mistake } \\
\text { Also: didn't mean to, goof, error, } \\
\text { shouldn't, accident, got mixed up }\end{array}$ & in packaging at the crayon factory & $\begin{array}{l}\text { the machine put all the same color } \\
\text { crayons into one box } \\
\text { Must include mention of machine OR all } \\
\text { the same color ending up in one container }\end{array}$ \\
\hline 2. hat & $\begin{array}{l}\text { I wanted it that way } \\
\text { Also: need }\end{array}$ & $\begin{array}{l}\text { so my ponytail could fit through the } \\
\text { hole } \\
\text { Give credit for "for your ponytail" }\end{array}$ & $\begin{array}{l}\text { so I cut a hole in it with my } \\
\text { scissors } \\
\text { Also: ripped it, anything about how I put the } \\
\text { hole there }\end{array}$ \\
\hline 3. phone & It's stuck & $\begin{array}{l}\text { because somebody spilled glue on it } \\
\text { Also: it was glued }\end{array}$ & $\begin{array}{l}\text { the glue ran into the crack and } \\
\text { pasted it together } \\
\text { Must include something about where the } \\
\text { glue went OR information about how it was } \\
\text { stuck together; "in it" alone is not enough. }\end{array}$ \\
\hline 4. puzzle & \multicolumn{3}{|c|}{ NE: All the other pieces fit in this puzzle. } \\
\hline 5. ketchup & $\begin{array}{l}\text { It was a mistake } \\
\text { Also: didn't mean to, goof, error, } \\
\text { shouldn't, accident, didn't know }\end{array}$ & $\begin{array}{l}\text { because she thought it was chocolate } \\
\text { in the bottle } \\
\text { Also: didn't know }\end{array}$ & $\begin{array}{l}\text { because the ketchup bottle and the } \\
\text { chocolate bottle look the same }\end{array}$ \\
\hline 6. clothes in bed & $\begin{array}{l}\text { She didn't mean to } \\
\text { Also: mistake, goof, error, } \\
\text { shouldn't, forgot, didn't want to }\end{array}$ & $\begin{array}{l}\text { but she was really tired so she fell } \\
\text { asleep without changing } \\
\text { Any of the three parts is enough for credit. } \\
\text { Also: didn't change }\end{array}$ & into her pajamas \\
\hline
\end{tabular}




\begin{tabular}{|c|c|c|c|}
\hline 7. orange juice & $\begin{array}{l}\text { He wanted orange juice } \\
\text { Also: need }\end{array}$ & $\begin{array}{l}\text { because milk makes him sick } \\
\text { Also: doesn't taste good, doesn't like milk, } \\
\text { allergic, tummy ache }\end{array}$ & $\begin{array}{l}\text { so he has to have his cereal with } \\
\text { juice instead }\end{array}$ \\
\hline 8. winter clothes & \multicolumn{3}{|c|}{ NE: He's wearing all his winter clothes. $\quad$ Don't give credit for “He thought it was winter.” } \\
\hline 9. turtle/nest & $\begin{array}{l}\text { He crawled in there } \\
\text { Also: crawled up, climbed in, went } \\
\text { in }\end{array}$ & $\begin{array}{l}\text { because he was looking for something } \\
\text { to eat } \\
\text { Also: hungry, wanted to eat, food }\end{array}$ & $\begin{array}{l}\text { he couldn't see what was in the } \\
\text { nest } \\
\text { Also: didn't know what was in there }\end{array}$ \\
\hline 10. door & $\begin{array}{l}\text { Regular doors are too big } \\
\text { for Julia } \\
\text { Should include mention of Julia's } \\
\text { size, incl. “she's little” }\end{array}$ & $\begin{array}{l}\text { because she's a mouse } \\
\text { Also: rat }\end{array}$ & $\begin{array}{l}\text { she can't reach the doorknob on a } \\
\text { big door }\end{array}$ \\
\hline 11. nose & He works as a clown & $\begin{array}{l}\text { he forgot to take it off } \\
\text { Also: left it on, still on, didn't take off }\end{array}$ & $\begin{array}{l}\text { because he didn't look in the } \\
\text { mirror }\end{array}$ \\
\hline 12. bed & \multicolumn{3}{|c|}{ NE: That bed is very comfortable. } \\
\hline 13. light switch & $\begin{array}{l}\text { She didn't want to use her } \\
\text { hands } \\
\text { Also: didn't feel like using her } \\
\text { hands }\end{array}$ & because they were sticky & $\begin{array}{l}\text { because some jelly squished out of } \\
\text { her sandwich } \\
\text { Should include the cause of the sticky } \\
\text { hands, any food is fine. }\end{array}$ \\
\hline
\end{tabular}




\begin{tabular}{|l|l|l|l|}
\hline 14. spin & $\begin{array}{l}\text { She's practicing } \\
\text { Also: training, getting ready }\end{array}$ & $\begin{array}{l}\text { so she will be ready for her dance } \\
\text { class } \\
\text { Also: to be a dancer, dance moves, for dance, } \\
\text { dance routine, for a dance, ballet, recital }\end{array}$ & $\begin{array}{l}\text { because when she practices, she } \\
\text { gets better }\end{array}$ \\
\hline 15. bucket & $\begin{array}{l}\text { She's pretending } \\
\text { Also: thinking, wanted, trying, to } \\
\text { act as }\end{array}$ & $\begin{array}{l}\text { Also: bucket as a hat } \\
\text { the blue bucket was a fairy crown }\end{array}$ & $\begin{array}{l}\text { so she could be a beautiful fairy } \\
\text { princess } \\
\text { Give E3 credit for “to be a fairy,” but not } \\
\text { for "she's wearing a fairy crown” }\end{array}$ \\
\hline 16. hat stomp & NE: People don't usually jump on hats. & \multicolumn{1}{|c|}{ Also: That's not right } \\
\hline
\end{tabular}




\section{Appendix F}

Coding Categories Used for Child Responses in Study 4

a) Agrees, nods head or says “oh”

Example: ADULT: He wanted orange juice because milk makes him sick. CHILD: Oh.

Example: ADULT: I wanted it that way so my ponytail could fit through the hole. CHILD: Oh.

Example: ADULT: People don’t usually jump on hats. CHILD: I never jumped on my hat.

b) Asks a follow-up question, including clarification questions

Example: ADULT: It's stuck because somebody spilled glue on it. CHILD: Why did somebody spill glue on it?

Example: ADULT: He wanted orange juice because milk makes him sick.

CHILD: Why does it make him sick?

Example: ADULT: It's stuck because somebody spilled glue on it and the glue ran into the crack and pasted it together. CHILD: So, we'll never be able to play with it?

Example: ADULT: He crawled in there because he was looking for something to eat. CHILD: What did he want to eat?

Example: ADULT: She’s practicing so she'll be ready for her dance class.

CHILD: Grownups take dance class?

c) Re-asks original question 
Example: CHILD (original question): Then why's his bed outside? ADULT:

That bed is very comfortable. CHILD: Yeah, but why is it outside then?

Example: CHILD (original question): Why is she stomping on your hat?

ADULT: People don't usually jump on hats. ADULT: But why is she?

Example: CHILD (original question): Why is she turning all the lights out?

ADULT: She didn't want to use her hands because they were sticky. CHILD:

Then why'd she turn all the lights out?

d) Provides own explanation

Example: ADULT: Yeah, he wanted orange juice. CHILD: He thought it was milk.

Example: ADULT: He wanted orange juice. CHILD: He made a mistake. Example: ADULT: She didn't want to use her hands because they were sticky because some jelly squished out of her sandwich. CHILD: And she had her hands full.

Example: ADULT: She didn't mean to. CHILD: Forgot to put her pajamas on. Example: ADULT: All the other pieces fit in that puzzle. CHILD: It goes in another puzzle, I know.

Example: ADULT: He's wearing all his winter clothes. CHILD: And that, and that's a mistake.

Example: ADULT: People don’t usually jump on hats. CHILD: Unless they're bad hats.

e) Smiles or Laughs

f) Disagrees with adult response 
Example: ADULT: That bed is very comfortable. CHILD: I don't think it's very warm.

Example: ADULT: That bed is very comfortable. CHILD: Well, it doesn't look so comfortable.

Example: ADULT: That bed is very comfortable. CHILD: It is not.

g) Provides additional on-topic supporting details

Example: ADULT: Yeah, she didn't want to use her hands because they were sticky because some jelly squished out of her sandwich. CHILD: Jelly is really sticky.

Example: ADULT: He crawled in there. CHILD: Silly turtle.

Example: ADULT: She didn't mean to but she was really tired so she fell asleep without changing into her pajamas. CHILD: She must have stayed up too late.

h) Changes the topic or asks for next item

Example: ADULT: Regular doors are too big for Julia because she is a mouse.

CHILD: Why did she have a sock for a mat?

Example: ADULT: It was a mistake in packaging at the crayon factory and the machine put all the same color crayons into one box. CHILD: I'm not really good at moons.

Example: ADULT: He works as a clown and he forgot to take it off. CHILD: Ah, hair's on my tongue!

Example: ADULT: She didn't want to use her hands. CHILD: Now, what's the next one? 
Example: ADULT: She didn't want to use her hands. CHILD: What's the next one?

Example: ADULT: She didn’t mean to but she was really tired so she fell asleep without changing. CHILD: What about the next story?

i) No response 


\section{REFERENCES}

Au, T.K., \& Romo L.F. (1999). Mechanical causality in children’s “folkbiology.” In D.L. Medin \& S. Atran (Eds.) Folkbiology (pp. 355-401). Cambridge, MA: The MIT Press.

Bakeman, R., \& Gottman, J. M. (1997). Observing interaction (2 ${ }^{\text {nd }}$ ed.). New York: Cambridge University Press.

Bloom, L., Merkin, S. \& Wootten, J. (1982). Wh-questions: Linguistic factors that contribute to the sequence of acquisition. Child Development, 53, 1084-1092.

Bonawitz, E. B. \& Lombrozo, T. (2007, July). Simplicity and probability in children’s causal explanations. Poster presented at the annual meeting of the Cognitive Science Society. Memphis, TN.

Brewer, W.F., Chinn, C.A. \& Samarapungavan, A. (1998) Explanation in scientists and children. Minds and Machines, 8, 119-136.

Brown, R. (1968). The development of wh questions in child speech. Journal of Verbal Learning and Behavior, 7, 279-290.

Brown, R. (1973). A first language: The early stages. Cambridge, MA: Harvard University Press.

Bullock, M., \& Gelman, R. (1979). Preschool children’s assumptions about cause and effect: Temporal ordering. Child Development, 50, 89-96.

Cairns, H. S., \& Hsu, J. R. (1978). Who, why, when and how: a development study. Journal of Child Language, 5, 477-488. 
Callanan, M.A., \& Oakes, L.M. (1992). Preschoolers’ questions and parents’ explanations: Causal thinking in everyday activity. Cognitive Development, 7, 213233.

Callanan, M.A., Perez-Granados, D., Barajas, N. \& Goldberg, J. (1999). “Why” questions in Mexican-descent children’s conversations with parents. Manuscript under review.

Carey, S. (1985). Conceptual change in childhood. Cambridge, MA: MIT Press.

Chouinard, M. M. (2007). Children's questions: A mechanism for cognitive development. Monographs of the Society for Research in Child Development, 72 (1, Serial No. 286).

Gopnik, A. (1998). Explanation as orgasm. Minds and Machines, 8, 101-118.

Gopnik, A., \& Schulz, L. (2004). Mechanisms of theory formation in young children. Trends in Cognitive Sciences, 8, 371-377.

Harris, P. L., \& Koenig, M. (2006). Trust in testimony: How children learn about science and religion. Child Development, 77, 505-524.

Hatano, G., \& Inagaki, K. (1993). Young children’s understanding of the mind-body distinction. Child Development, 64(5), 1534-1549.

Hickling A.K., \& Wellman, H.M. (2001). The emergence of children’s causal explanations and theories: Evidence from everyday conversation. Developmental Psychology, 37 (5), 668-683.

Hood, L., \& Bloom, L. (1979). What, when, and how about why: A longitudinal study of early expressions of causality. Monographs of the Society for Research in Child Development, 44 (6, Serial No. 181). 
Isaacs, N. (1930). Children’s “why” questions. In S. Isaacs (Ed.), Intellectual growth in young children (pp. 291-349). London: George Routledge \& Sons.

Keil, F. C. (1998). Words, moms, and things: Language as a road map to reality. Commentary for Monographs of the Society for Research in Child Development, 63 (1, Serial No. 253).

Kelemen, D. (1999). The scope of teleological thinking in preschool children. Cognition, 70, 241-272.

Kelemen, D., Callanan, M. A., Casler, K., \& Pérez-Granados, D. R. (2005). Why things happen: Teleological explanations in parent-child conversations. Developmental Psychology, 41, 251-264.

Kemler Nelson, D. G., Egan, L. C., \& Holt, M. B. (2004). When children ask, "What is it?” What do they want to know about artifacts? Psychological Science, 15, 384-389.

Klima, E. S., \& Bellugi, U. (1966). Syntactic regularities in the speech of children. In J. Lyons \& R. J. Wales (Eds.), Psycholinguistics papers. Edinburgh, Scotland: Edinburgh University Press.

Kuczaj, S.A. (1976). -ing, -s, and -ed: A study of the acquisition of certain verb inflections (Doctoral dissertation, University of Minnesota, 1977). Dissertation Abstracts International, 37, 5400-5401.

Lagattuta, K. H., \& Wellman, H. M. (2002). Differences in early parent-child conversations about negative versus positive emotions: Implications for the development of psychological understanding. Developmental Psychology, 38, 564580. 
Landis, J. R., \& Koch, G. G. (1977). The measurement of observer agreement for categorical data. Biometrics, 33, 159-174.

Lombrozo, T. (in press). Simplicity and probability in causal explanation, Cognitive Psychology.

MacWhinney, B. (1995). The CHILDES Project: Tools for analyzing talk (2 ${ }^{\text {nd }}$ ed.). Hillsdale, NJ: Erlbaum.

MacWhinney, B., \& Snow, C. (1985). The child language data exchange system. Journal of Child Language, 12, 271-296.

MacWhinney, B., \& Snow, C. (1990). The child language data exchange system: An update. Journal of Child Language, 17, 457-472.

Mandler, J. M. (1988). How to build a baby: On the development of an accessible representational system. Cognitive Development, 3, 113-136

Mills, C. M., \& Keil, F. C. (2004). Knowing the limits of one’s understanding: The development of an awareness of an illusion of explanatory depth. Journal of Experimental Child Psychology, 87, 1-32.

Murphy, G. L. \& Medin, D. L. (1985). The role of theories in conceptual coherence. Psychological Review, 92, 284-316.

Piaget, J. (1930). The child's conception of physical causality. London: Routledge \& Kegan Paul.

Piaget, J. (1954). The construction of reality in the child. New York: Basic Books.

Rozenblit, L., \& Keil, F. C. (2002). The misunderstood limits of folk science: An illusion of explanatory depth. Cognitive Science, 26, 521-562.

Sachs, J. (1983). Talking about the there and then: The emergence of displaced reference 
in parent-child discourse. In K. E. Nelson (Ed.), Children's language, Vol. 4, Hillsdale, NJ: Lawrence Erlbaum Associates.

Samarapungavan, A. (1992). Children’s judgments in theory choice tasks: Scientific rationality in childhood. Cognition, 45, 1-32.

Searle, J. R. (1969). Speech Acts. Cambridge: Cambridge University Press.

Shultz, T. R., \& Mendelson, R. (1975). The use of covariation as a principle of causal analysis. Child Development, 46, 394-399.

Signorella, M. L., \& Liben, L. S. (1984). Recall and reconstruction of gender-related pictures: Effects of attitude, task difficulty, and age. Child Development, 55, 393-405.

Simon, H. A. (2001) "Seek and ye shall find” How curiosity engenders discovery. Designing for Science. pp 5-20.

Simons, D. J., \& Keil, F. C. (1995). An abstract to concrete shift in the development of biological thought: The insides story. Cognition, 56, 129-163.

Sobel, D. M., \& Kirkham, N. Z. (2006). Blickets and babies: The development of causal reasoning in toddlers and infants. Developmental Psychology, 42, 1103-1115.

Tyack, D., \& Ingram, D. Children’s production and comprehension of questions. Journal of Child Language, 4, 211-224.

Wellman, H., \& Gelman, S. A. (1998). Knowledge acquisition in foundational domains. In W. Damon \& D. Kuhn \& R. Siegler (Eds.), Cognition, perception and language (5th ed., Vol. 2, pp. 523-573). New York: Wiley.

Werner, H., \& Kaplan, B. (1963). Symbol formation. New York: Wiley. 